\title{
The selective formation of $\alpha$-Fe(II) sites on Fe-zeolites through one-pot synthesis
}

\author{
Max L. Bols, ${ }^{\ddagger}, \mathrm{a}$ Julien Devos, ${ }^{\star a}$ Hannah M. Rhoda, ${ }^{\mathrm{b}}$ Dieter Plessers, ${ }^{\mathrm{a}}$ Edward I. Solomon, ${ }^{*, \mathrm{~b}}$ \\ Robert A. Schoonheydt, ${ }^{*, a}$ Bert F. Sels, ${ }^{*, a}$ and Michiel Dusselier*,a \\ a Department of Microbial and Molecular Systems, KU Leuven, 3001 Heverlee, Belgium. ${ }^{\text {b Department of }}$ \\ Chemistry, Stanford University, Stanford, California 94305, United States. ${ }^{\$}$ These authors contributed equally to \\ this work.
}

\section{Supporting Info}

\section{S1. Synthesis Methods}

$\underline{\text { S1.1. Synthesis of CHA precursors for post-synthetic exchange. }}$

Two CHA zeolites were synthesized according to the recipe used in ref 1 . The former was named 'CHA', while the latter is named $\mathrm{CHA}^{*}$ in further post-synthetic preparations. A molar batch composition of 1Si:0.067Al:0.22TMAda ${ }^{+}: 0.13 \mathrm{Na}^{+}: 0.35 \mathrm{OH}^{-}: 12.5 \mathrm{H}_{2} \mathrm{O}$ was targeted using FAU (Zeolyst international, CBV720) as the $\mathrm{Si}$ and $\mathrm{Al}$ source. $53.3 \mathrm{~g}$ of aqueous $\mathrm{N}, \mathrm{N}, \mathrm{N}$-trimethyladamantylammonium hydroxide (TMAdaOH) solution (25 wt.\%, Sachem), $9.96 \mathrm{~g}$ of $\mathrm{NaOH}$ solution (15 wt.\%, from $>98 \mathrm{wt} . \% \mathrm{NaOH}$ pellets, Sigma-Aldrich), and $12.7 \mathrm{~g}$ of deionized water (18.2 M $\Omega . \mathrm{cm}^{-1}$ ) were mixed in a $125 \mathrm{~mL}$ Teflon lined stainless steel autoclave (Parr Instruments) and homogenized. $20.6 \mathrm{~g}$ of the zeolite Y precursor were then added, and the mixture was homogenized, sealed off and oven-heated at $160{ }^{\circ} \mathrm{C}$ for 4 days under static conditions. After synthesis, the reactors were cooled and the solids were recovered by centrifugation (6000rpm, $\geq 5 \mathrm{~min})$ and washed at least 3 times $\left( \pm 50 \mathrm{~mL}\right.$ solvent per g solids) with deionized water $\left(18.2 \mathrm{M} \Omega . \mathrm{cm}^{-1}\right)$ until the supernatant shows $\mathrm{pH}$ below 9. After a final washing step with acetone the solids were oven-dried overnight at $100^{\circ} \mathrm{C}$, yielding the as-synthesized materials. The OSDA in the zeolite pores was removed by calcination in air at $580^{\circ} \mathrm{C}$ for $6 \mathrm{~h}$ after ramping the furnace at $1^{\circ} \mathrm{C} / \mathrm{min}$ from ambient conditions (LV9/11, Nabertherm).

\section{$\underline{\text { S1.2. Post-synthetic ion-exchange and Fe introduction }}$}

To prepare the H-CHA precursor material the as-synthesized Na-CHA was ion exchanged three times with $100 \mathrm{ml} / \mathrm{g}$ of a 1 $\mathrm{M} \mathrm{NH} 4 \mathrm{NO}_{3}$ solution for six hours and then washed with deionized water. The same ion exchange procedure was applied to K-FER (TSZ-700 KOA) to obtain $\mathrm{NH}_{4}$-FER. The sample was then calcined overnight at $550^{\circ} \mathrm{C}$ in $\mathrm{O}_{2}$ flow with a heating ramp of $5{ }^{\circ} \mathrm{C} / \mathrm{min}$ to $550{ }^{\circ} \mathrm{C}$ to convert the $\mathrm{NH}_{4}$ cations to protons. $\mathrm{NH}_{4}-\mathrm{FER}, \mathrm{NH}_{4}{ }^{*} \mathrm{BEA}$, (CP814E, Zeolyst) H-FAU (CBV720, Zeolyst) and as synthesized Na-CHA were also calcined before further use.

Fe was introduced in H-CHA or Na-CHA, H-FAU, H-FER and H-*BEA using various procedures. The resulting samples and their corresponding recipes of iron introduction can be found in Table S1. The method of iron introduction is indicated in the form 'iron introduction method'. The preparations using $\mathrm{Fe}(\mathrm{acac})_{3}$ in toluene at room temperature are analogous to those in refs 1-6, although larger iron loadings were generally used for this study. All preparations consisted of the addition of an amount of aqueous or organic solution of an Fe(III) salt or complex to an amount of dried, calcined zeolite, corresponding to $\sim 22 \mathrm{ml}$ solution per gram dry zeolite. The mixture was then stirred with a magnetic stirring bar at 700 rotations per minute at a certain temperature for 24 hours. After stirring the solution was centrifuged and the recovered material was washed trice in the solvent. Then the samples were calcined in static air at $580^{\circ} \mathrm{C}$ for 30 hours with a heating ramp of $1.6^{\circ} \mathrm{C} / \mathrm{min}$. The chemical composition and methanol extraction data of all samples are summarized in Table S2.

\section{$\underline{\text { S1.3. Hydrothermal Synthesis of Fe-CHA (one-pot) }}$}

Synthesis conditions and batch compositions for all Fe-CHA preparations with iron introduced in the batch are found in Table S3. The labels are introduced in the experimental section (Section 2.1.2). Next to the synthesis types for 'IZC' and 'Am', the additional labels 'Al-IZC, Si-IZC, Na-IZC and 'Step' are listed in Table S3. The first two labels indicate the use of 
another FAU source during IZC. For 'Al-IZC' a US-Y with Si/Al=5.8 was used (CBV712, Zeolyst) and for 'Si-IZC' US-Y with $\mathrm{Si} / \mathrm{Al}=40$ was used (CBV780, Zeolyst). In 'Na-IZC', an equimolar quantity of TMAda ${ }^{+}$and $\mathrm{Na}^{+}$are used as OSDA and CBV720 as Si and Al source, keeping other synthesis variables constant. The 'Step' synthesis type is executed according to the stepwise synthesis method for CHA synthesis explained in ref 7.

For each synthesis N,N,N-Trimethyl-1-Adamantammonium hydroxide (SACHEM), additional deionized water (18.2 $\left.\mathrm{M} \Omega . \mathrm{cm}^{-1}\right)$ and -sometimes- aqueous $\mathrm{NaOH}$ solution (20 wt $\%$, from $>98 \mathrm{wt} \% \mathrm{NaOH}$ pellets) were added directly in a $23 \mathrm{ml}$ Teflon liner reactor, followed by brief internal stirring (PTFE stirring bar, 20x6mm) of the solution and introduction of the source materials. The Si source was added first, followed by the Al source in the case of amorphous sources ('Am'-type). The complete mixture was internally stirred until a homogenous mixture was obtained ( $\sim 1 \mathrm{~min}$. for IZC syntheses, $\sim 5 \mathrm{~min}$. for Am* syntheses). Finally, the iron source was introduced and the mixture was vigorously stirred (600rpm; $\sim 5 \mathrm{~min}$.). The Teflon liners were inserted into the corresponding stainless steel autoclaves (Acid digestion vessel 4749, Parr instruments) and heated in a forced convection oven (Heratherm, ThermoSientific) at $160^{\circ} \mathrm{C}$. After synthesis, the reactors were cooled and the solids were recovered by centrifugation $(6000 \mathrm{rpm}, \geq 5 \mathrm{~min})$ and washed at least 3 times $( \pm 50 \mathrm{~mL}$ solvent per g solids) with deionized water $\left(18.2 \mathrm{M} \Omega . \mathrm{cm}^{-1}\right)$ until the supernatant's $\mathrm{pH}$ dropped below 9. After a final washing step with acetone the solids were oven-dried overnight at $100^{\circ} \mathrm{C}$, yielding the as-synthesized materials. The OSDA in the zeolite pores was removed by calcination in air at $580^{\circ} \mathrm{C}$ for $6 \mathrm{~h}$ after ramping the furnace at $1{ }^{\circ} \mathrm{C} / \mathrm{min}$ from ambient conditions (LV9/11, Nabertherm).

\section{S2. Additional notes on hydrothermal syntheses of Fe-CHA (one-pot method)}

\section{$\underline{\text { S2.1. In-depth characterization of baseline syntheses }}$}

Calcined baseline one-pot preparations (Fe loading $=\sim 300 \mu \mathrm{mol} / \mathrm{g}$ ) show P-XRD with characteristic peaks for detemplated crystalline CHA (Figure S1). The materials have a typical microporosity as observed from nitrogen physisorption $(>0.28$ $\mathrm{cm}^{3} / \mathrm{g}$, Figure S2) and not much octahedral $\mathrm{Al}$ is apparent from ${ }^{27} \mathrm{Al}$ SS MAS NMR (Figure S3). The small, sharp peak centered at $0 \mathrm{ppm}$ is typical for $\mathrm{Al}$ that can be reinserted into the framework. ${ }^{8}$ The latter may indicate a very small fraction of mobile $\mathrm{Al}$ at calcination conditions, ${ }^{9}$ despite the assumption that most $\mathrm{Al}$ mobility only occurs after higher temperature $\left(>650^{\circ} \mathrm{C}^{\circ}\right.$ ) treatments (cfr. Section 4.3). From ${ }^{29} \mathrm{Si} \mathrm{SS}$ MAS NMR (figure $\mathrm{S} 3$ ), one can observe $\mathrm{Q}^{4} \mathrm{Si}(4 \mathrm{Si})$ and $\mathrm{Q}^{4} \mathrm{Si}(3 \mathrm{Si}, 1 \mathrm{Al})$ peaks at respectively $-111 \mathrm{ppm}$ and $-105 \mathrm{ppm}$. A peak at $-101.5 \mathrm{ppm}$ can also be assigned to $\mathrm{Q}^{4}(3 \mathrm{Si}, 1 \mathrm{Al})$. No peaks between -92 and $-100 \mathrm{ppm}$ typically assigned to $\mathrm{Q}^{3}$ or $\mathrm{Q}^{2}$ silicons have been discerned, indicating only low amounts of silanol defects (silanol nests) and Al-O-Si-O-Al (next-nearest-neighbour Al) configurations. The latter observation is also valid for other siliceous CHA $(\mathrm{Si} / \mathrm{Al}>10){ }^{10,11}$

\section{$\underline{\text { S2.2. Combination method of post-synthetic exchange and one-pot method }}$}

The sample labeled 'FAU[TA] $]_{349}-\mathrm{IZC}_{259}$ ' (Table 1) is made from Fe-exchanged FAU (CBV720, Zeolyst) according to standard procedures (Section S1.2) followed by interzeolite conversion of this Fe-exchanged source according to the methods described in section S1.3 and with batch composition: $1 \mathrm{Si}: 0.067 \mathrm{Al}: 0.37 \mathrm{TMAda}^{+}: 0.37 \mathrm{OH}^{-}: 0.023 \mathrm{Fe}: 26.6 \mathrm{H}_{2} \mathrm{O}$. Apart from the Fe contained in the FAU source, no additional $\mathrm{Fe}$ is added. More synthetic details on the procedure and synthetic conditions are given in Table S3. No significant advantages were found using this strategy on the methanol yield after an activation- $\mathrm{N}_{2} \mathrm{O}-\mathrm{CH}_{4}$ reaction cycle (Table $\left.\mathrm{S} 4\right)$.

\section{$\underline{\text { S2.3. Effect of iron on synthesis yields }}$}

The one-pot method with iron in the synthesis mixture produces a higher solid yield than an identical synthesis without iron ( $94 \%$ vs $74 \%$ yield). The association of silica to iron via Si-O-Fe bonds (or of silica with aluminum via Si-O-Al bonds) suppresses the solubility of silica and effectively includes more Si into the solid phase. ${ }^{12}$ This is particularly relevant in our syntheses with high concentrations of hydroxide and silica. Similar tendencies are also found for (Al containing) IZC syntheses.

\section{$\underline{\text { S2.4. Effect of silica on iron speciation during crystallization }}$}

The one-pot synthesis procedure to yield as-made zeolites with framework incorporated iron is remarkably efficient given the starting point from stable iron oxide precipitates in alkaline media. After addition of iron nitrate nonahydrate to the alkaline synthesis mixture the typical orange-brown color related to Fe precipitation $\left(\mathrm{Fe}(\mathrm{OH})_{3}\right)$ is observed almost instantly, although it takes more time when $\mathrm{Fe}(\mathrm{acac})_{3}$ is used as Fe source (several minutes at $600 \mathrm{rpm}$ stirring). The tendency to form iron-silicate precipitates in preparations from highly concentrated dissolved silica creates circumstances that promote dissolution of iron hydroxides due to Fe-O-Si bond formations in silica precipitates at elevated (synthesis) temperatures. ${ }^{12}$ Note the parallel with alumina in $\mathrm{Si}$ rich alkaline media, as $\mathrm{Si}-\mathrm{O}-\mathrm{Al}$ bonds are believed to form more easily than $\mathrm{Si}-\mathrm{O}-\mathrm{Si}$ from dissolved species. ${ }^{13}$ In case of favorable conditions for crystallization (cfr. in this work), precipitated $\mathrm{Fe}$ and $\mathrm{Al}$ reservoirs are entirely consumed as witnessed in this work by the nearly complete assembly of framework $\mathrm{Fe}$ (and $\mathrm{Al}$ ) after 
synthesis and the absence of $\mathrm{Fe}$ (and $\mathrm{Al}$ ) in the synthesis liquid solution, which is nearly transparent. However, in reaction mixtures were crystallization is absent or hampered (e.g. Step $(\mathrm{N})_{804}$ or $\operatorname{IZC}(\mathrm{O})_{180}$ ), precipitated Fe is not completely consumed, as also indicated by the pale red-brown color of the synthesis liquor which is not observed in successful crystallizations. Therefore, selection of favorable conditions of hydrothermal synthesis is important to obtain complete consumption of $\mathrm{Fe}$ and $\mathrm{Al}$ sources. ${ }^{14}$ In the earlier days of hydrothermal iron zeotype synthesis, the focus was put on avoiding Fe hydrolysis/precipitation, either by separate ageing of alkaline $\mathrm{Si}$ (and $\mathrm{Al}$ ) sources and acidic (monomeric) $\mathrm{Fe}$ sources, ${ }^{15}$ or by using organic iron(III) clusters with ligands such as acetylacetone or oxalate anions. ${ }^{16}$ These techniques are believed to give advantages in difficult crystallization conditions, such as in the case of 'IZC(A) ${ }_{825}$ ' and 'IZC(N) ${ }_{830}$ ' (figure S6) in this work.

\section{S3. Stoichiometry of $\alpha-\mathrm{Fe}$ (II) to $\alpha-0, \mathrm{CH}_{4}$ activation, and methanol extraction}

On $\mathrm{N}_{2} \mathrm{O}$ activated $\sim 100 \% \alpha$-Fe(II) samples, the reaction of $\alpha$-O with methane results in the loss of absorption features of $\alpha$ $\mathrm{O}$ at 17000,27000 and $37000 \mathrm{~cm}^{-1}$ and the appearance of new bands at 15000 and $32000 \mathrm{~cm}^{-1}$. To see how these changes in UV-Vis-NIR absorption correlate to methanol yield from extraction we plotted the area under the difference spectrum from $5700 \mathrm{~cm}^{-1}$ to $15000 \mathrm{~cm}^{-1}$ against methanol yield in figure $\mathrm{S} 8$ for both the step of $\alpha-\mathrm{O}$ formation and the room temperature methane reaction. Using this energy range avoids the inclusion of charge transfer bands with very strong extinction coefficients on the UV side and vibrational bands on the NIR side. If these reaction steps proceeded with equal conversion and selectivity and along the same active sites and reaction intermediates, the points should lie on a single line.

Looking first at the plot in figure S8D (using the difference of the spectra before and after $\mathrm{CH}_{4}$ reaction at room temperature) we see a scatterplot without linear correlation $\left(\mathrm{R}^{2}=0.05\right)$. However, it does correlate significantly with methanol $/ \mathrm{Fe}$ $\left(\mathrm{R}^{2}=0.53\right.$ ) (figure $\mathrm{S} 8 \mathrm{~F}$ ). This $\mathrm{R}^{2}$ is slightly improved to 0.54 by adding the iron loading as a variable, but the adjusted $\mathrm{R}^{2}$ then drops from 0.51 to 0.50 and the iron loading variable is not significant ( $\mathrm{p}$-value $=0.47$ ). Methane activation can be expected to produce a mixture of $\mathrm{Fe}(\mathrm{III})$ and $\mathrm{Fe}(\mathrm{II})$ from $\alpha-\mathrm{O} \cdot{ }^{17} \mathrm{For} \mathrm{Fe}(\mathrm{II}), \mathrm{d}-\mathrm{d}$ bands are spin-allowed and give strong absorption in the NIR, compensating for the loss of the $\alpha-\mathrm{O}$ with absorption at $~ 8000 \mathrm{~cm}^{-1}$. Overall the change in UV-Vis-NIR absorption by methane activation does not lead to a strong correlation with methanol yield, possibly because the new absorption from $\mathrm{Fe}(\mathrm{III})$ and the lost absorption from Fe(IV) cancel out. At higher methanol/Fe more methane activation products floats around per iron and this may interact with a large proportion of other oxidized $\mathrm{Fe}(\mathrm{III})$ (as well as with $\alpha$-O) reducing it to $\mathrm{Fe}$ (II) with strong NIR absorption. Probably this conversion dominates the changes in the NIR absorption leading to the strong correlation with methanol/Fe while methanol yield does not correlate.

To test the ability of oxidized spectators to react with oxidation product we did an $\mathrm{N}_{2} \mathrm{O}-\mathrm{CH}_{4}$ reaction cycle on sample $\mathrm{Am}(\mathrm{N})_{512}$ after treating the sample in $\mathrm{He}$ at $900^{\circ} \mathrm{C}$ and then in $\mathrm{O}_{2}$ at $550^{\circ} \mathrm{C}$. The methanol yield decreased from 55 to 34 $\mu$ mol/g relative to an $\mathrm{N}_{2} \mathrm{O}-\mathrm{CH}_{4}$ reaction cycle after helium only. Clearly, oxidized spectator iron can thus be reduced by $\mathrm{CH}_{4}$ oxidation products. The existence of redox active iron besides $\alpha-\mathrm{Fe}(\mathrm{II}) / \alpha-\mathrm{O}$ on $\mathrm{Am}(\mathrm{N})_{512}$ is evident in figure $\mathrm{S} 10$, where $\mathrm{Fe}$ (II) with strong d-d transitions is converted to Fe(III) with mainly CT absorption at higher energy. Successive oxidation of methanol is also demonstrated by the formation and extraction of formaldehyde in steam extraction $(\mathrm{m} / \mathrm{z}=29)$ of the methane oxidation products in ref 1 . However, the $\mathrm{O}_{2}$ generated oxidation sites cannot activate methane to yield extractable methanol. Replacing the $\mathrm{N}_{2} \mathrm{O}$ step by an $\mathrm{O}_{2}$ step at $550^{\circ} \mathrm{C}$ (known not to oxidize $\alpha$-Fe(II)), no detectable amount of methanol could be recovered in $\mathrm{CH}_{3} \mathrm{CN} / \mathrm{H}_{2} \mathrm{O}$ extraction from $\mathrm{IZC}(\mathrm{A}) 490$.

In conclusion, the changes in the UV-Vis-NIR spectrum without looking at specific bands (i.e. deconvolution) cannot be used to reliably quantify the reacted active sites for room temperature methane activation. This is unlikely to be related to the presence of another active site though, in which case the correlation with methanol should be more pronounced. To be more concrete this explanation must be backed by a quantitative analysis of methane products that goes further than just methanol, and a quantification of reacted methane per iron. The current data suggest that this will likely reveal a complex scheme of interactions.

Looking at the difference between spectra before and after $\mathrm{N}_{2} \mathrm{O}$ reaction at $180^{\circ} \mathrm{C}$, we now more clearly see a correlation between methanol yield and the area under the difference spectra $\left(\mathrm{R}^{2}=0.41\right)$. Against methanol/Fe the $\mathrm{R}^{2}$ is 0.30 , but this largely explains the same variance as that captured by the methanol variable. Adding the iron loading variable gives an adjusted $R^{2}=0.48$, but using the iron loading alone gives an $R^{2}=0$. The stronger correlation with methanol yield for the $\mathrm{N}_{2} \mathrm{O}$ reaction indicates that the weak correlation found for the methane reaction is mostly affected by 'chaotic' contributions to the difference spectra and less by overoxidation affecting the methanol yield. The latter would also affect the correlation of methanol yield with the UV-Vis-NIR absorption changes in the $\mathrm{N}_{2} \mathrm{O}$ reaction. This supports the interpretation in the preceding paragraph. Probably the conditions used in the $\mathrm{N}_{2} \mathrm{O}$ reaction $\left(25\right.$ minutes, $35 \% \mathrm{~N}_{2} \mathrm{O}$ at 1 atmosphere, $\left.180^{\circ} \mathrm{C}\right)$ 
mostly react $\alpha-\mathrm{Fe}$ (II) to $\alpha-\mathrm{O}$ and oxidize other $\mathrm{Fe}$ (II) only to a small extent. While the linear trend is there, there are strong deviations at higher Fe loadings. For materials where higher Fe content coincides with a lowered methanol/Fe ratio not much absorption difference remains despite a sustained amount of extracted methanol. This shows up in figure S8 as the outliers in the blue triangle. The deviations from the expected correlation are likely due to the oxidation of spectator $\mathrm{Fe}^{2+}$ generating large changes in the absorption spectrum - especially relative to the conversion of $\alpha$-Fe to $\alpha-\mathrm{O}$ which both absorb similarly in the NIR. For other samples at high iron loadings a diminishing methanol extraction at increasing difference in absorption occurs (rectangular box in figure S8). In these cases oxidized spectators probably impede the formation and/or trapping of suitable methanol precursors as the end product. Note that in the above, we can have deviations from the expected linear trends in both directions. Points that are found on the linear trend therefore do not necessarily approach single-site, but may end up there through error cancellation.

It is still possible that different $\mathrm{Fe}$ sites that just like $\alpha$-Fe(II) do not form active oxygen from $\mathrm{O}_{2}$ but do so from $\mathrm{N}_{2} \mathrm{O}$ participate in the higher loading samples, but this will always be a possibility in samples on which the iron is not fully characterized. Because we do not require another active site to explain the results, the simplest explanation involving one active site is reasonable. Unfortunately the area under the difference spectra and/or methanol yield are not suitable to accurately quantify $\alpha-\mathrm{Fe}(\mathrm{II}), \alpha-\mathrm{O}$, or $\mathrm{CH}_{4}$ reaction products, but they do demonstrate how spectroscopic analysis rapidly becomes challenging when poorly understood components enter the reaction system. The analysis demonstrates the importance of selectively introducing single and well dispersed oxidation sites for high selectivity in partial oxidation reactions with small, diffusive products. On the other hand, other less reactive oxidation sites may also be beneficial depending on the intended application. ${ }^{18}$

Alongside overoxidation other factors also decrease the methanol yield and decrease the methanol: $\alpha$-Fe ratio. $\alpha$-Fe(II) is not fully converted to $\alpha$-O. In ref 1 only $\sim 74 \%$ of $\alpha$-Fe(II) was converted to $\alpha$-O after 20 minutes in $35 \% \quad \mathrm{~N}_{2} \mathrm{O} / \mathrm{He}(1$ atmosphere) at $160{ }^{\circ} \mathrm{C}$. With the currently used procedure $\left(25\right.$ minutes, $\left.180^{\circ} \mathrm{C}\right)$ this could be brought up to $84 \%$ (figure S9). The remainder $16 \%$ is a $\mathrm{Fe}$ (II) doublet that possibly includes contaminated $\alpha$-Fe(II) sites. Hence the methanol: $\alpha$-Fe ratio is already limited to 0.84 . This value of 0.84 was obtained for $\sim 100 \% \alpha$-Fe(II) samples and is likely affected by the sample's iron loading and speciation as well. Furthermore the liquid extraction procedure may not recover all adsorbed methanol precursors. In ref $1,26 \%$ more methanol could be recovered through steam extraction than through the $\mathrm{CH}_{3} \mathrm{CN} / \mathrm{H}_{2} \mathrm{O}$ extraction used here, and we see a similar difference here $(135 \mu \mathrm{mol} / \mathrm{g}$ vs $183 \mu \mathrm{mol} / \mathrm{g})$. Again, the effectiveness of the extraction may depend on iron loading and speciation as well. For this work, because of the large number of samples it was not feasible to use the lengthy (30 hours) steam extraction procedure. We did, however, test the correlation of $\alpha-\mathrm{Fe}$ (II) to $\alpha$ $\mathrm{O}$ conversion (as measured by change in the Kubelka-Munk transformed UV-Vis difference spectra of samples activated with $\mathrm{N}_{2} \mathrm{O}$ at different temperature) with extractable methanol through steaming (measured by the $\mathrm{m} / \mathrm{z}=31$ signal on mass spectrometry) for a $1.86 \mathrm{wt}$ \% Fe IZC Fe-CHA sample (see figure S27). The correlation is positive, but not linear. At higher conversion of $\alpha-\mathrm{Fe}$ (II) to $\alpha-\mathrm{O}$, more methanol is recovered per $\alpha-\mathrm{O}$. This can be interpreted in several ways. There could be multiple active sites, although that is not apparent from the spectroscopy. There could also be second order effects, where multiple $\alpha$-O participate in the path to extractable methanol precursors. Finally, at low $\alpha$-Fe(II) conversion, the leftover $\mathrm{N}_{2} \mathrm{O}$ interacting with $\alpha-\mathrm{Fe}$ (II) may be reactive towards reactive intermediates from the $\mathrm{CH}_{4}$ activation, and lower the methanol yield. To give a definitive answer, a full understanding of the carbon balance and a full picture of the reaction network must be developed. 


\section{S4. Additional modifications to post-treatments and activation procedures}

Modifying the post-preparation treatment by introducing an additional high temperature oxidation $\left(\mathrm{O}_{2}\right)$ or reduction $\left(\mathrm{H}_{2}\right)$ step did not bring further improvements. While such steps did oxidize or reduce spectator iron, as seen in figure S9, these did not transform into $\alpha$ - $\mathrm{Fe}$ (II). An extra $\mathrm{H}_{2}$ treatment step thus transformed some $\mathrm{Fe}$ (III) to $\mathrm{Fe}$ (II) that was not yet autoreduced through $\mathrm{O}_{2}$ desorption in helium autoreduction. $\mathrm{H}_{2}$ can be more suitable to reduce disperse $\mathrm{Fe}(\mathrm{III})$. It can take one oxygen to form $\mathrm{H}_{2} \mathrm{O}$, while $\mathrm{O}_{2}$ desorption requires the recombination of two oxygens which may be kinetically difficult. The $\mathrm{H}_{2}$ step did improve methanol yield somewhat, but as explained in S3, this was likely due to suppressed overoxidation of the methanol products. The methanol yields achieved by treating respectively sample IZC $(A)_{315}$ and $\operatorname{IZC}(\mathrm{N})_{305}$ in $\mathrm{H}_{2}$ at $700^{\circ} \mathrm{C}$ after $\mathrm{O}_{2} 580^{\circ} \mathrm{C}$ were 58 and $59 \mu \mathrm{mol} / \mathrm{g}$, up from 37 and $39 \mu \mathrm{mol} / \mathrm{g}$ after $\mathrm{He} 650^{\circ} \mathrm{C}$. With a $\mathrm{He} 900^{\circ} \mathrm{C}$ step the yields were increased up to 105 and $116 \mu \mathrm{mol} / \mathrm{g}$. Therefore the removal of oxygen ligands does not appear to be the limiting step in $\alpha$ $\mathrm{Fe}(\mathrm{II})$ formation from its $\mathrm{Fe}(\mathrm{III})$ precursors.

Once formed by a $900^{\circ} \mathrm{C}$ step, the $\alpha$-Fe(II) sites can be recovered by heating in dry $\mathrm{O}_{2}, \mathrm{H}_{2}$ or $\mathrm{He}$ flow to $<650^{\circ} \mathrm{C}$ (figure S11). Probably temperatures of $\sim 550^{\circ} \mathrm{C}$ are also sufficient as indicated in ref 19 . The $900^{\circ} \mathrm{C}$ step thus induces an irreversible conversion, converting a higher energy state to a more stable one but requiring a high barrier. We argue that this step is the redistribution of framework aluminum.

\section{S5. Comparison between one pot-samples from amorphous Si \& Al source and one-pot samples from IZC}

Comparing the Am and IZC samples in Table S3, they do not differ in iron retention. Comparing them in Table S4 and figures S1, S2, S4, S5, S6, their methanol yields, methanol/Fe ratios and crystallinity are similar. On figure S7 the similar samples from Am or IZC preparation also lie close together. An exception may be IZC $(N)_{290}$ and Am(N)289 (and IZC(N) 274$)$. No large differences are seen in their UV-Vis-NIR spectra (figure S12).

We also tracked iron along the post-synthesis procedures in a one-pot preparation made from amorphous $\mathrm{Al}$ and $\mathrm{Si}$ and ${ }^{57} \mathrm{Fe}(\mathrm{acac})_{3}$ with $6 \mathrm{~K}$ Mössbauer spectroscopy. After synthesis and drying at $200^{\circ} \mathrm{C}$ the spectrum resembles that of the IZC sample, indicating a similar starting point as that obtained through IZC (figure S13 B). In the 'Am' preparation there is an additional contribution from a second six-line pattern that grows in further at $350^{\circ} \mathrm{C}$ (figure $\mathrm{S} 13 \mathrm{~A}$ ). This difference with the 'IZC' spectrum in $\mathrm{S} 13 \mathrm{~B}$ is probably because of the higher drying temperature $\left(200^{\circ} \mathrm{C}\right.$ for 'Am' vs $100^{\circ} \mathrm{C}$ for ' $\left.\mathrm{IZC}^{\prime}\right)$. Moving up to $500^{\circ} \mathrm{C}$ all iron seems to have left the framework and a small $\alpha$-Fe(II) doublet may be present. The other features resemble those observed on the IZC sample after $\mathrm{He} 650^{\circ} \mathrm{C}$ (figure $\mathrm{S} 13 \mathrm{C}$ ). Moving up to $580^{\circ} \mathrm{C}$ some intensity is moved into the now clearly resolvable $\alpha$-Fe(II) doublet. The peak to the left hand side of the $\alpha$-Fe(II) doublet has shoulders on both sides and is likely composed of multiple peaks of several doublets. This was also the case for the IZC samples although the distribution is different. This may be related to the absence of $\mathrm{O}_{2}$ during the drying of the Am samples, affecting the iron species formed (after drying in helium up to $580^{\circ} \mathrm{C}$ the Am samples were black due to coking).

\section{S6. Mass spectrometry and UV-Vis-NIR spectra during/between drying, calcination and autoreduction}

Intermittent UV-Vis-NIR spectra after the IZC, drying, calcination and autoreduction steps are shown for IZC $\left({ }^{57} \mathrm{~A}\right)_{288}$ in figure S14. Corresponding mass spectra are shown in figure S15. During the calcination step, organic template and chemisorbed water are fully removed (see disappearance NIR bands in figure S14 and mass spectra in figure S15). The vibrational features of hydroxyl groups in the $4300-4700 \mathrm{~cm}^{-1}$ range of silanol and BAS become visible after calcination. After $\mathrm{He} 900^{\circ} \mathrm{C}$ the silanol and BAS vibrations are partially lost. While silanols are known to dehydrate to form $\mathrm{Si}-\mathrm{O}-\mathrm{Si}$ bridges at $>800^{\circ} \mathrm{C}$, the Brönsted acid sites are likely decreased as $\mathrm{H}^{+}$is replaced by $\mathrm{Fe}^{2+}$ and $\mathrm{Fe}^{3+}$ cations which now compensate lattice anionic charge $\left(\mathrm{AlO}_{4}^{-}\right)_{\mathrm{FW}}$ instead of extraframework oxygen ligands $\left(\mathrm{O}^{2-}\right)_{\mathrm{EF}}$. Both these processes release $\mathrm{H}_{2} \mathrm{O}$, as is detected by MS (figure $\mathrm{S} 15$ ). $\mathrm{O}_{2}$ is also released, likely linked to autoreduction of $\mathrm{Fe}(\mathrm{III})$ to $\mathrm{Fe}(\mathrm{II})$. We quantified the $\mathrm{MS} \mathrm{O}_{2}$ signal and scaled it for experimental conditions (He flow) and sample properties (mass of sample and iron loading) to obtain $9.50 * 10^{-9} \mathrm{~mA}^{*} \mathrm{ml}_{\text {flow }} / \mu$ molfe (figure $\mathrm{S} 15$ panel $\mathrm{E}$ ). We similarly quantified the $\mathrm{O}_{2}$ released in a helium TPD of $\alpha$-O to obtain $2.05 * 10^{-8} \mathrm{~mA}^{*} \mathrm{ml}_{\text {flow }} / \mu$ molFe (figure S15 panel D).

For the $\alpha-\mathrm{O}$ TPD we assume the following recombination reaction:

$2 \mathrm{Fe}(\mathrm{IV})=\mathrm{O} \rightarrow 2 \alpha-\mathrm{Fe}(\mathrm{II})+\mathrm{O}_{2}$

For the $\mathrm{O}_{2}$ released in the autoreduction at $800-900^{\circ} \mathrm{C}$ we assume:

$4 \mathrm{Fe}(\mathrm{III})(\mathrm{OEF}) \mathrm{X}+2 \rightarrow 4 \mathrm{Fe}(\mathrm{II})(\mathrm{OEF}) \mathrm{X}+\mathrm{O}_{2}$ 
If we assume $84 \%$ of $\alpha$ - $\mathrm{Fe}$ (II) forms $\mathrm{Fe}(\mathrm{IV})=\mathrm{O}$ (see figure S9) we can use the TPD experiment to calibrate the $\mathrm{O}_{2}$ desorption in panel $\mathrm{E}$ and derive that an amount of $\mathrm{Fe}$ (III) corresponding to $78 \%$ of all $\mathrm{Fe}$ in the sample is reduced to $\mathrm{Fe}$ (II) in the $900^{\circ} \mathrm{C}$ He step (i.e. was not yet reduced in the $<650^{\circ} \mathrm{C}$ treatments). We determine in section $\mathrm{S} 7$ from Mössbauer that $12 \%$ of Fe was already $\alpha-\mathrm{Fe}(\mathrm{II})$ after $\mathrm{He} 650^{\circ} \mathrm{C}$ (figure $\mathrm{S} 16$ ). This $78 \%$ is close to the $(84-12) \%=72 \%$ of iron that is reduced in the $900^{\circ} \mathrm{C}$ step according to the Mössbauer data.

\section{S7. Deconvolution and analysis of Mössbauer spectra}

Here we further analyze the $6 \mathrm{~K}$ Mössbauer spectra on $\operatorname{IZC}\left({ }^{57} \mathrm{~A}\right) 288$ after the $\mathrm{He} 650^{\circ} \mathrm{C}$ step and after the $\mathrm{He} 900^{\circ} \mathrm{C}$ step (figure $\mathrm{S} 16 \mathrm{~A}$ and $\mathrm{B}$ ). After the $\mathrm{He} 650^{\circ} \mathrm{C}$ step, a complex spectrum is observed in LT Mössbauer with hyperfine components. The $\alpha-\mathrm{Fe}$ (II) doublet is clearly discernable and accounts for $12 \%$ of the Fe in the sample. There are two other $\mathrm{Fe}(\mathrm{III})$ components in the spectrum, one doublet that accounts for $19 \%$ of the remaining $\mathrm{Fe}$ and a complicated hyperfine component that accounts for the rest $(69 \%)$ of Fe. These two Fe(III) components have the same isomer shift and quadrupole splitting at low temperature and collecting this sample at room temperature results in the hyperfine component collapsing into the $\mathrm{Fe}(\mathrm{III})$ doublet observed at $6 \mathrm{~K}$ (Figure S16 C). Therefore the remaining $88 \%$ of Fe in this sample is from an individual $\mathrm{Fe}(\mathrm{III})$ component that gives both a doublet and hyperfine component at low temperature.

After the $\mathrm{He} 900^{\circ} \mathrm{C}$ step, the $\alpha$-Fe(II) doublet represents $72 \%$ of iron. Another $\mathrm{Fe}(\mathrm{II})$ doublet represents $12 \%$ of iron. Note that this can also be $\alpha-\mathrm{Fe}$ (II) that is contaminated by ligands that have entered the sample during preparation for Mössbauer (e.g. $\mathrm{H}_{2} \mathrm{O}$ leading to partial hydration, see figure S24), therefore the $\alpha-\mathrm{Fe}(\mathrm{II})$ concentration is at least $72 \%$, and at most $84 \%$. The remaining $7 \%$ of iron is in a hyperfine component which probably represents some form of $\mathrm{Fe}(\mathrm{III})$ oxide clusters.

\section{S8. FT-IR spectroscopy}

FT-IR spectra were measured on the calcined $\operatorname{IZC}\left({ }^{57} \mathrm{~A}\right)_{288}$ sample; one before and one after $900{ }^{\circ} \mathrm{C}$ treatment according to the experimental section (Section 2.4.8.). The spectra differ strongly in the $\mathrm{OH}$ stretching region (figure S20). Features at $3734 \mathrm{~cm}^{-1}, 3605 \mathrm{~cm}^{-1}$, and around $3577 \mathrm{~cm}^{-1}$ are partially lost. These are respectively $\mathrm{OH}$ stretches of defect and exterior surface related silanols $\left(3734 \mathrm{~cm}^{-1}\right)$ and multiple types of non-H-bonded AlFw related Brönsted acid sites (BAS). ${ }^{20}$ The clear resolution of the $\mathrm{OH}$ stretches points at the dehydrated states of the material, although some molecular water is still present as indicated by the $\sim 1620 \mathrm{~cm}^{-1}$ feature in figure S21. ${ }^{20}$ The difference FTIR spectrum in figure S23 also indicates a small decrease in an absorption feature at $3700 \mathrm{~cm}^{-1}$. Features at $3670-3690 \mathrm{~cm}^{-1}$ have been linked to $\mathrm{OH}$ stretches of $\mathrm{Al}-$ containing extra-framework species, ${ }^{21}$ but this seems not very strongly substantiated. Finally, in the region of the fundamental framework vibrations (figure S22) a feature clearly grows in at $905 \mathrm{~cm}^{-1}$. This can be related to silanol nest that have been cured into strained Si-O-Si bonds. A small feature at $653 \mathrm{~cm}^{-1}$ related to framework aluminum may be lost as well. $^{22}$

\section{s9. Comparison $\mathrm{CHA} \&$ *BEA}

Comparing $\mathrm{Fe}-* \mathrm{BEA}$ and $\mathrm{Fe}-\mathrm{CHA}$ we see that iron retention is not a problem in *BEA while it was in CHA for postsynthesis iron introduction (table 1). This is probably because of the larger 12MR channels in BEA versus the 8MR windows in CHA. Beyond iron introduction both behave similarly in post treatment steps. With calcination a first cohort of $\alpha-\mathrm{Fe}$ (II) is formed, and prolonging the calcination does not change the iron speciation (figure S17). After $900^{\circ} \mathrm{C}$ in $\mathrm{He}$ a large majority of $\mathrm{Fe}$ can form $\alpha-\mathrm{Fe}$ (II) and this coincides with the loss of silanols and BAS. The $\alpha-\mathrm{Fe}(\mathrm{II})$ is similarly resistant to oxidation by $\mathrm{O}_{2}$ at $580^{\circ} \mathrm{C}$ (figure $\mathrm{S} 17$ ).

\section{S10. Effect of $\mathrm{Na}$ on $\alpha-\mathrm{Fe}$ (II) formation from one-pot synthesis}

Using an equimolar amount of $\mathrm{TMAdaOH}$ and $\mathrm{NaOH}$ under baseline synthesis conditions $(\mathrm{OH} / \mathrm{Si}=0.36$; starting from CBV720), a crystalline CHA is formed (IZC+Na(N)590, Table S3). When this calcined CHA is subjected to inert (Argon) treatment at $580^{\circ} \mathrm{C}$ (and consecutive $\mathrm{N}_{2} \mathrm{O}$ treatment), some signatures for $\alpha$-Fe(II) are visible from DR-UV-Vis-NIR spectroscopy (figure S18, left), and $53 \mu$ mol methanol per gram could be extracted after the $\mathrm{N}_{2} \mathrm{O} \mathrm{CH}_{4}$ reaction sequence. However, such species were not detected in UV-Vis-NIR after inert treatment at $900^{\circ} \mathrm{C}$ (figure $\mathrm{S} 18$ right), and the methanol yield dropped to $27 \mu \mathrm{mol} / \mathrm{g}$. This drop in methanol yield is not a result of structural collapse. P-XRD demonstrates structural integrity of the materials (figure S19). Likely, the effect of $\mathrm{Na}$ on the $\mathrm{Fe}$ speciation is detrimental to $\alpha$-Fe(II) selectivity in the $900^{\circ} \mathrm{C}$ treatment.

Sodium can reduce the mobility of $\mathrm{Al}$ in $\mathrm{CHA}$, expected to occur at $>850^{\circ} \mathrm{C}$ (4.2) through its favorable positioning in (double) 6 membered rings, ${ }^{23,24}$ and this could hamper the formation of the second cohort of $\alpha$-Fe(II). However, we observe a drop in methanol yield while the latter explanation would only result in an unchanged yield. Possibly the interaction of 
sodium, iron and aluminum at $900^{\circ} \mathrm{C}$ gives rise to the decreased methanol yield. This interaction only does so from elevated iron loadings; On a sample with lower Fe loading where Fe was introduced on a Na-CHA material post synthesis (Na$\mathrm{CHA}(\mathrm{WN})_{136}$ ), a methanol yield of $48 \mu \mathrm{mol} / \mathrm{g}$ was obtained using the reaction cycle with $\mathrm{He} 900^{\circ} \mathrm{C}$. This is similar to the 53 $\mu \mathrm{mol} / \mathrm{g}$ after $\mathrm{He} 580^{\circ} \mathrm{C}$ obtained on $\mathrm{IZC}+\mathrm{Na}(\mathrm{N})_{590}$ and exceeds the $27 \mu \mathrm{mol} / \mathrm{g}$ yield observed on the $\mathrm{He} 900^{\circ} \mathrm{C}$ reaction cycle on $\mathrm{IZC}+\mathrm{Na}(\mathrm{N})_{590}$ with higher $\mathrm{Fe}$ loading. Maybe $\mathrm{Al}$ redistributes to stabilize sodium instead of iron at $900^{\circ} \mathrm{C}$, especially at high loadings of iron.

\section{S11. DFT Calculations and model Mössbauer parameters}

A DFT cluster model of $\left[\mathrm{Fe}(\mathrm{OH})_{2}\right]^{+}$in a CHA cage was prepared by replacing a single $\mathrm{Si}$ T-site with an $\mathrm{Al}$ atom and positioning an extra-lattice $\left[\mathrm{Fe}(\mathrm{OH})_{2}\right]^{+}$nearby. The full optimized cluster is shown in figure S25. The Mössbauer parameters of this $\mathrm{Fe}(\mathrm{III})$ site were calculated to have an IS $=0.36 \mathrm{~mm} / \mathrm{s}$ and a QS $=-2.65 \mathrm{~mm} / \mathrm{s}$.

Structure optimized DFT cluster models were also generated for an Fe(III)-O in either the cha cage or inside a d6r and their Mössbauer parameters were calculated. In both the d6MR and the CHA cage the Fe-O structure optimized to give Mössbauer parameters with an IS $=\sim 0.5 \mathrm{~mm} / \mathrm{s}$ and a $\mathrm{QS}=\sim-4.0 \mathrm{~mm} / \mathrm{s}$. The optimized cluster models are included in the supplementary data.

A tri-coordinated $\mathrm{Fe}_{\mathrm{FW}}$ could also be envisioned by the dehydration process shown below, and a model was similarly evaluated using DFT. Mössbauer parameters were calculated to be IS $=0.19 \mathrm{~mm} / \mathrm{s}$ and QS $=+3.5 \mathrm{~mm} / \mathrm{s}$ before dehydration and $\mathrm{IS}=0.16 \mathrm{~mm} / \mathrm{s}$ and $\mathrm{QS}=+3.5 \mathrm{~mm} / \mathrm{s}$ after dehydration. The optimized cluster models are included in the supplementary data.

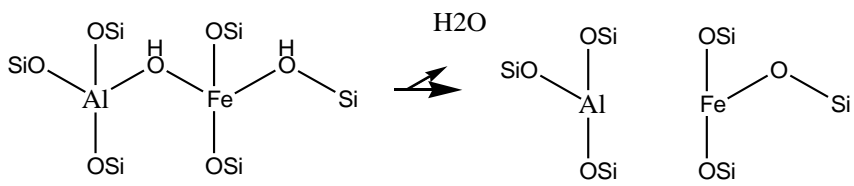

Based on the calculated Mössbauer parameters, none of these models satisfactorily fit the experimental Fe(III) parameters (IS $=0.22 \mathrm{~mm} / \mathrm{s}$ QS $=+1.9 \mathrm{~mm} / \mathrm{s}$ ) observed in the $\operatorname{IZC}\left({ }^{57} \mathrm{~A}\right)_{288}$ sample post calcination is the $\mathrm{Fe}(\mathrm{OH})_{2}$ model. In another set of DFT calculations we started from the lattice Fe(III) and looked at the first hydrolysis step. A series of DFT small models was created using the Fe intralattice model (top left, 1A in Figure S26) as a start for the intralattice site. As shown in A, the model with the bridging Si-OH-Fe(III) (2A) reproduced the similar IS and the large positive QS. For the molecules with one water molecule added, only model B4 (Terminal Fe-OH 4-coordinate) was energetically accessible but this site has a large negative QS and a larger IS than A2, which are not consistent with the experimental data. The perturbed intralattice Fe(III) models A2 and B4 in figure S26 are both four coordinate Fe(III) sites with one Fe-OH bond. It is interesting to consider the ligand field origin of their different symmetry and predicted Mössbauer parameters. $\mathrm{H}_{2} \mathrm{O}$ binding generates a terminal $\mathrm{OH}$ with a strong $\mathrm{Fe}(\mathrm{III})-\mathrm{OH}$ bond $(1.84 \AA$ A). $\mathrm{Fe}$ is shifted out of the plane of the bridging oxygen atoms by $\sim 0.9 \AA$. In the motif where the site is protonated to generate a bridging Fe(III)-OH-Si structure, the Fe(III)-OH-Si bond is weaker (1.96 $\AA$ ) and Fe is located more in the trigonal plane of the bridging oxygen atoms ( $\sim .3 \AA$ out of plane). The signs and strengths of the QS reflect these structural changes.

The other structures in figure S26 are not energetically accessible and additionally do not reproduce the experimental Mössbauer parameters. For the molecules with two waters added in C, again the Mössbauer parameters do not reproduce the experimental data and were excluded. 


\section{S12. Additional figures and tables}

Table S1: Post-synthetic Fe introductions in zeolites: overview of introduction methods.

\begin{tabular}{|c|c|c|c|c|c|}
\hline Preparation $^{\mathrm{A}}$ & $\begin{array}{l}\text { Precursor } \\
\text { material }^{\mathrm{A}}\end{array}$ & solvent $^{\mathrm{B}}$ & $\begin{array}{l}\mathrm{Fe}(\mathrm{III}) \\
\text { source }^{\mathrm{C}}\end{array}$ & $\begin{array}{c}\mathrm{Fe}(\mathrm{III}) \text { added } \\
(\mu \mathrm{mol} / \mathrm{g})\end{array}$ & $\begin{array}{c}\text { Temperature } \\
\left({ }^{\circ} \mathrm{C}\right)\end{array}$ \\
\hline CHA(TA) 57 & $\mathrm{H}-\mathrm{CHA}$ & Toluene & $\mathrm{Fe}(\mathrm{acac})_{3}$ & 304 & 25 \\
\hline $\mathrm{CHA}(\mathrm{TA})^{2}{ }_{95}$ & CHA(TA) 57 & Toluene & $\mathrm{Fe}(\mathrm{acac})_{3}$ & 304 & 25 \\
\hline $\mathrm{CHA}\left(\mathrm{TA}-105^{\circ} \mathrm{C}\right)_{124}$ & $\mathrm{H}-\mathrm{CHA}$ & Toluene & $\mathrm{Fe}(\mathrm{acac})_{3}$ & 294 & 105 \\
\hline CHA(WA) 92 & H-CHA & Water & $\mathrm{Fe}(\mathrm{acac})_{3}$ & 294 & 25 \\
\hline $\mathrm{CHA}(\mathrm{WN})_{60}$ & H-CHA & Water & $\mathrm{Fe}\left(\mathrm{NO}_{3}\right)_{3}$ & 304 & 25 \\
\hline $\mathrm{CHA}^{*}(\mathrm{WN})_{52}$ & $\mathrm{H}-\mathrm{CHA} *$ & Water & $\mathrm{Fe}\left(\mathrm{NO}_{3}\right)_{3}$ & 301 & 25 \\
\hline $\mathrm{Na}-\mathrm{CHA} *(\mathrm{WN})_{136}$ & $\mathrm{Na}-\mathrm{CHA} *$ & Water & $\mathrm{Fe}\left(\mathrm{NO}_{3}\right)_{3}$ & 301 & 25 \\
\hline FAU(TA) 221 & H-FAU & Toluene & $\mathrm{Fe}(\mathrm{acac})_{3}$ & 637 & 25 \\
\hline $\operatorname{FER}(\mathrm{TA})_{30}$ & H-FER & Toluene & $\mathrm{Fe}(\mathrm{acac})_{3}$ & 300 & 25 \\
\hline BEA(TA) 193 & $\mathrm{H}-* \mathrm{BEA}$ & Toluene & $\mathrm{Fe}(\mathrm{acac})_{3}$ & 213 & 25 \\
\hline
\end{tabular}

Table S2: Post-synthetic introduction of Fe in zeolites: chemical composition and methanol extraction data.

\begin{tabular}{|c|c|c|c|c|c|c|c|c|c|c|}
\hline \multirow[b]{2}{*}{ Preparation $^{A}$} & \multicolumn{2}{|c|}{ Conditions } & \multicolumn{5}{|c|}{ Output } & \multicolumn{3}{|c|}{ Methanol Extraction Data ${ }^{\mathrm{C}}$} \\
\hline & $\mathbf{S i} / \mathbf{A l}$ & $\mathrm{Fe}(\mu \mathrm{mol} / \mathrm{g})$ & $\mathrm{Si} / \mathrm{Al}$ & $\begin{array}{c}\mathbf{F e} \\
\text { (wt.\%) }\end{array}$ & $\mathrm{Fe} / \mathrm{Al}$ & $\begin{array}{c}\mathbf{F e} \\
(\mu \mathrm{mol} / \mathrm{g})\end{array}$ & Fe retention ${ }^{B}$ & $\begin{array}{l}\mathrm{MeOH}^{\mathrm{C}} \\
(\mu \mathrm{mol} / \mathrm{g})\end{array}$ & $\begin{array}{l}\mathrm{MeOH} / \mathrm{Fe} \\
\text { (mol:mol) }\end{array}$ & $\begin{array}{l}\text { MeOH/Al } \\
\text { (mol:mol) }\end{array}$ \\
\hline $\mathrm{CHA}(\mathrm{TA})_{57}$ & 10 & 304 & 10 & 0.32 & 0.04 & 57 & $19 \%$ & 15 & 0.26 & 0.010 \\
\hline $\mathrm{CHA}(\mathrm{TA})^{2}{ }_{95}$ & 10 & 304 (x 2) & 11 & 0.53 & 0.07 & 95 & $16 \%$ & 21 & 0.23 & 0.014 \\
\hline $\begin{array}{l}\text { CHA(TA- } \\
\left.105^{\circ} \mathrm{C}\right)_{124}\end{array}$ & 10 & 294 & 12 & 0.69 & 0.10 & 124 & $42 \%$ & 42 & 0.34 & 0.034 \\
\hline $\mathrm{CHA}(\mathrm{WA})_{92}$ & 10 & 294 & 9 & 0.52 & 0.06 & 92 & $31 \%$ & 32 & 0.35 & 0.021 \\
\hline $\mathrm{CHA}(\mathrm{WN})_{60}$ & 10 & 304 & 10 & 0.33 & 0.04 & 60 & $20 \%$ & 21 & 0.35 & 0.014 \\
\hline $\mathrm{CHA}^{*}(\mathrm{WN})_{52}$ & 11 & 301 & 9 & 0.29 & 0.03 & 52 & $17 \%$ & 13 & 0.25 & 0.009 \\
\hline $\mathrm{Na}-\mathrm{CHA} *(\mathrm{WN})_{136}$ & 11 & 301 & 9 & 0.76 & 0.09 & 136 & $45 \%$ & 48 & 0.35 & 0.032 \\
\hline $\mathrm{FAU}(\mathrm{TA})_{221}$ & 13 & 637 & 15 & 1.23 & 0.22 & 221 & $35 \%$ & 3 & 0.01 & 0.002 \\
\hline $\operatorname{FER}(\mathrm{TA})_{30}$ & 7 & 300 & 7 & 0.17 & 0.02 & 30 & $10 \%$ & 0 & 0 & 0 \\
\hline $\mathrm{BEA}(\mathrm{TA})_{193}$ & 13 & 213 & 13 & 1.08 & 0.16 & 193 & $91 \%$ & 30 & 0.16 & 0.026 \\
\hline
\end{tabular}

${ }^{A}$ Standard post-synthesis Fe-introduction methods see section S1.2, the labeling is explained in Table S1. ${ }^{B}$ Ratio of Fe in the recovered solid product / Fe added in the preparation procedure. ${ }^{C}$ Methanol from liquid extractions (see methods 2.3). 
Table S3: Properties of synthetic SSZ-13 (CHA) preparations.

\begin{tabular}{|c|c|c|c|c|c|c|c|c|c|c|c|c|c|c|c|c|}
\hline Preparation $^{A}$ & $\mathrm{Si} / \mathrm{Al}_{\mathbf{B}}{ }^{\mathrm{B}}$ & $\mathbf{O S D A}^{+} / \mathbf{S i}$ & $\mathrm{Na}^{+} / \mathrm{Si}$ & $\mathrm{OH}^{-} / \mathrm{Si}$ & $\mathrm{H}_{2} \mathrm{O} / \mathrm{Si}$ & $\mathrm{Fe}^{3+} / \mathrm{Si}$ & $\mathrm{Fe} / \mathrm{Al}_{\mathrm{B}}{ }^{\mathrm{B}}$ & $\begin{array}{l}\mathrm{Fe}_{\mathrm{B}} \mathrm{C} \\
(\mu \mathrm{mol} / \mathrm{g})\end{array}$ & $\begin{array}{l}\text { Temp. }{ }^{\mathrm{D}} \\
\left({ }^{\circ} \mathrm{C}\right)\end{array}$ & $\begin{array}{l}\text { Time } \\
\text { (days) }\end{array}$ & $\begin{array}{l}\text { Stirring } \\
\text { mode }\end{array}$ & Phase $^{E}$ & Yield $^{F}$ & $\mathrm{Si} / \mathrm{Al}_{\mathrm{Fr}}{ }^{\mathrm{G}}$ & $\begin{array}{l}\mathrm{Fe}_{\mathrm{Fr}}^{\mathrm{H}} \\
(\mu \mathrm{mol} / \mathrm{g})\end{array}$ & $\begin{array}{l}\text { Fe-retention } \\
\left(\mathrm{Fe}_{\mathrm{F}} / \mathrm{Fe}_{\mathrm{B}} \%\right)\end{array}$ \\
\hline$\overline{I Z C(A)_{315}}$ & $\bar{~} 13$ & "0.36 & 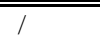 & "0.36 & 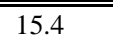 & "0.019 & 0.25 & 294 & $\overline{c 160}$ & 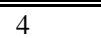 & static & 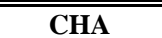 & 0.83 & & 315 & 107 \\
\hline $\operatorname{IZC}\left({ }^{57} \mathrm{~A}\right)_{288}$ & 13 & 0.33 & 1 & 0.33 & 14.1 & 0.016 & 0.22 & 252 & 160 & 4 & static & CHA & 1 & 12 & 288 & 114 \\
\hline $\operatorname{IZC}(\mathrm{N})_{290}$ & 13 & 0.36 & l & 0.36 & 15.5 & 0.018 & 0.24 & 285 & 160 & 4 & static & CHA & 0.96 & 11 & 290 & 102 \\
\hline $\operatorname{IZC}(\mathrm{N})_{274}$ & 13 & 0.36 & I & 0.36 & 15.5 & 0.017 & 0.24 & 284 & 160 & 4 & static & CHA & 0.84 & 13 & 274 & 96 \\
\hline $\operatorname{IZC}(\mathrm{O}))_{180}$ & 13 & 0.36 & I & 0.36 & 15.6 & 0.017 & 0.24 & 284 & 160 & 4 & static & CHA & 0.91 & 13 & 180 & 63 \\
\hline $\operatorname{IZC}(\mathrm{A})_{490}$ & 13 & 0.36 & l & 0.36 & 15.5 & 0.035 & 0.47 & 549 & 160 & 4 & static & CHA & 0.93 & 13 & 490 & 89 \\
\hline $\operatorname{IZC}(\mathrm{N})_{542}$ & 13 & 0.36 & l & 0.36 & 15.5 & 0.037 & 0.48 & 565 & 160 & 4 & $600 \mathrm{rpm}$ & CHA & 1.09 & 13 & 542 & 96 \\
\hline $\operatorname{IZC}(N)_{621}$ & 13 & 0.34 & / & 0.34 & 14.4 & 0.039 & 0.52 & 605 & 160 & 4 & $600 \mathrm{rpm}$ & CHA & 0.91 & 13 & 621 & 103 \\
\hline $\operatorname{IZC}(A)_{822}^{\dagger}$ & 13 & 0.36 & / & 0.36 & 15.5 & 0.055 & 0.73 & 848 & 160 & 4 & static & CHA(FAU) & 1 & 12 & 825 & 97 \\
\hline $\operatorname{IZC}(\mathrm{N})_{830}^{\dagger}$ & 13 & 0.36 & 1 & 0.36 & 15.6 & 0.055 & 0.73 & 853 & 160 & 4 & static & FAU + CHA & 1 & 12 & 830 & 97 \\
\hline $\operatorname{IZC}(A)_{1398}^{\dagger}$ & 13 & 0.36 & 1 & 0.36 & 15.5 & 0.090 & 1.2 & 1398 & 160 & 4 & static & FAU + Am & 1 & 1 & 1 & 0 \\
\hline 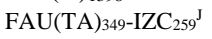 & 13 & 0.37 & I & 0.37 & 26.6 & 0.023 & 0.3 & 349 & 160 & 4 & $600 \mathrm{rpm}$ & СНА & I & 13 & 259 & 74 \\
\hline $\operatorname{IZC}(\mathrm{A})_{278}$ & 13 & 0.33 & l & 0.34 & 14.1 & 0.016 & 0.22 & 255 & 160 & 4 & $600 \mathrm{rpm}$ & CHA & 0.91 & 12 & 278 & 109 \\
\hline $\operatorname{IZC}(\mathrm{N})_{305}$ & 13 & 0.36 & l & 0.36 & 15.8 & 0.018 & 0.24 & 284 & 160 & 4 & static & CHA & 1 & 11 & 305 & 107 \\
\hline $\mathrm{Am}(\mathrm{A})_{289}$ & 15 & 0.34 & / & 0.34 & 15.3 & 0.017 & 0.25 & 266 & 160 & 4 & static & CHA & 0.95 & 9 & 289 & 108 \\
\hline $\mathrm{Am}(\mathrm{N})_{289}$ & 15 & 0.34 & / & 0.34 & 15.1 & 0.017 & 0.25 & 267 & 160 & 4 & static & CHA & 1.00 & 10 & 289 & 108 \\
\hline $\operatorname{Am}(N)_{512}$ & 15 & 0.34 & I & 0.34 & 15.5 & 0.034 & 0.51 & 535 & 160 & 4 & $600 \mathrm{rpm}$ & CHA & 0.97 & 13 & 512 & 96 \\
\hline $\operatorname{Am}(\mathrm{A})_{542}$ & 15 & 0.34 & I & 0.34 & 15.3 & 0.034 & 0.51 & 532 & 160 & 4 & static & CHA & 1 & 12 & 542 & 102 \\
\hline $\operatorname{Am}(\mathrm{A})_{776^{\dagger}}$ & 15 & 0.34 & I & 0.34 & 15.3 & 0.051 & 0.77 & 798 & 160 & 4 & static & CHA & 1 & 13 & 776 & 97 \\
\hline $\mathrm{Am}(-)_{0}$ & 15 & 0.35 & 1 & 0.35 & 17.5 & 1 & 1 & 1 & 160 & 4 & $600 \mathrm{rpm}$ & CHA & 0.75 & 11 & 0 & 1 \\
\hline $\operatorname{IZC}(-)_{0}$ & 15 & 0.35 & 1 & 0.35 & 12.8 & 1 & 1 & I & 160 & 4 & $600 \mathrm{rpm}$ & CHA & 0.73 & 10 & 0 & 1 \\
\hline Al-IZC(A) $)_{1163^{\dagger}}$ & 6 & 0.42 & 0.32 & 0.73 & 48.8 & 0.082 & 0.47 & 1163 & 160 & 10 & $600 \mathrm{rpm}$ & FAU +* & 1 & 1 & 1 & I \\
\hline Al-IZC(A) $)_{1163(2)}{ }^{\dagger}$ & 6 & 1.03 & 0.32 & 1.34 & 67.1 & 0.082 & 0.47 & 1163 & 160 & 6 & $600 \mathrm{rpm}$ & $\begin{array}{c}\text { FAUt } \\
\text { CHA+* }\end{array}$ & I & I & I & I \\
\hline Si-IZC $(\mathrm{A})_{274}$ & 40 & 0.33 & 1 & 0.33 & 14.2 & 0.017 & 0.67 & 274 & 160 & 4 & $600 \mathrm{rpm}$ & CHA & 1 & 1 & 1 & 1 \\
\hline Si-IZC $(\mathrm{N})_{418}$ & 40 & 0.35 & 1 & 0.35 & 16.7 & 0.026 & 1.03 & 418 & 160 & 4 & Static & CHA & 0.80 & 1 & 1 & 1 \\
\hline $\operatorname{Step}(\mathrm{N})_{804}{ }^{\mathrm{K}}$ & 14 & 0.20 & 0.60 & 0.65 & 16.3 & 0.031 & 0.43 & 486 & 160 & 4 & Static & CHA & 0.57 & 8.4 & 804 & 166 \\
\hline $\operatorname{Step}(\mathrm{N})_{561}{ }^{\mathrm{K}}$ & 14 & 0.15 & 0.62 & 0.62 & 17.7 & 0.018 & 0.25 & 277 & 160 & 4 & Static & $\begin{array}{c}\text { CHA } \\
(+\mathbf{A m} *)\end{array}$ & 0.49 & 6.8 & 561 & 202 \\
\hline $\mathrm{Na}-\mathrm{IZC}(\mathrm{N})_{540}$ & 13 & 0.18 & 0.18 & 0.36 & 17.4 & 0.033 & 0.44 & 522 & 160 & 2 & Static & CHA & 0.94 & 11.9 & 540 & 103 \\
\hline
\end{tabular}

${ }^{A}$ For the labeling of the preparations see methods 2.1.2. The dagger $(\dot{T})$ symbol indicates non-fully crystalline CHA materials.

${ }^{B}$ Molar ratios in the preparation batch procedure.

${ }^{C} \mathrm{Fe}_{B}=\mathrm{Fe}$ added in the preparation procedure in $\mu$ mol $\mathrm{Fe}$ per gram of zeolite sources (initial $\mathrm{g}\left(\mathrm{SiO}_{2}+\mathrm{AlO}_{2}\right)_{d r y} / g$ ).

${ }^{D}$ Temp $.\left({ }^{\circ} \mathrm{C}\right)=$ Temperature of hydrothermal synthesis oven in degrees Celsius.

${ }^{E}$ As determined by Powder X-ray diffraction. Traces between brackets. 'Am.' = Significant amorphous fraction.

${ }_{F}^{F}$ Yield $=[$ dry product weight $(\mathrm{g}) *(1-0.2$ wt. fraction $\mathrm{OSDA})] /\left[\right.$ initial $\left.\mathrm{g}\left(\mathrm{SiO}_{2}+\mathrm{AlO}_{2}\right)_{d v y}\right]$.

${ }^{G} \mathrm{Si} / \mathrm{A} \mathrm{F}_{\mathrm{Fr}}$ : molar Si to Al ration in the obtained solids, assuming 100\% framework Si and Al (cfr. NMR evidence).

${ }^{H} \mathrm{Fe}_{F r}=\mathrm{Fe}$ in the recovered solid product in $\mu \mathrm{mol} \mathrm{Fe}$ per gram of obtained calcined materials.

${ }^{I} \mathrm{Fe}$-retention as ratio of $\mathrm{Fe}$ in the recovered solid product/Fe added in the preparation procedure.

${ }^{J}$ The synthesis ' $F A U(T A)_{349}-I Z C_{259}$ ' is explained in $S 2.2$.

${ }^{K}$ Alternative recipe according to ref 7 . 
Table S4: One pot Fe-CHA preparations: chemical composition and methanol extraction data.

\begin{tabular}{|c|c|c|c|c|c|c|c|}
\hline Preparation $^{\mathbf{A}}$ & $\mathrm{Si} / \mathbf{A l}$ & $\mathrm{Fe}($ wt. \%) & $\mathbf{F e} / \mathbf{A l}^{\mathrm{B}}$ & $\begin{array}{c}\text { Fe } \\
(\mu \mathrm{mol} / \mathrm{g})\end{array}$ & $\begin{array}{l}\mathrm{MeOH}^{\mathrm{B}} \\
(\mu \mathrm{mol} / \mathrm{g})\end{array}$ & $\begin{array}{c}\mathrm{MeOH} / \mathrm{Fe} \\
\text { (mol ratio) }\end{array}$ & $\begin{array}{c}\mathrm{MeOH} / \mathrm{Al} \\
\text { (mol ratio) }\end{array}$ \\
\hline $\operatorname{IZC}(\mathrm{A})_{315}$ & 13 & 1.76 & 0.27 & 315 & 105 & 0.33 & 0.089 \\
\hline $\operatorname{IZC}\left({ }^{57} \mathrm{~A}\right)_{288}$ & 12 & 1.61 & 0.23 & 288 & 105 & 0.37 & 0.085 \\
\hline $\operatorname{IZC}(\mathrm{N})_{290}$ & 11 & 1.62 & 0.22 & 290 & 112 & 0.38 & 0.084 \\
\hline $\mathrm{IZC}(\mathrm{N})_{274}$ & 13 & 1.53 & 0.23 & 274 & 128 & 0.47 & 0.108 \\
\hline $\mathrm{IZC}(\mathrm{O})_{180}$ & 13 & 1.01 & 0.15 & 180 & 76 & 0.42 & 0.063 \\
\hline $\mathrm{IZC}(\mathrm{A})_{490}$ & 13 & 2.74 & 0.43 & 490 & 134 & 0.27 & 0.116 \\
\hline \multirow{2}{*}{$\mathrm{IZC}(\mathrm{N})_{542}$} & \multirow{2}{*}{13} & \multirow{2}{*}{3.02} & \multirow{2}{*}{0.45} & \multirow{2}{*}{542} & 76 & 0.14 & 0.063 \\
\hline & & & & & 94 & 0.17 & 0.078 \\
\hline $\mathrm{IZC}(\mathrm{N})_{621}$ & 13 & 3.47 & 0.54 & 621 & 127 & 0.2 & 0.108 \\
\hline $\mathrm{IZC}(\mathrm{A})_{825} \dagger$ & 12 & 4.61 & 0.66 & 825 & 65 & 0.08 & 0.053 \\
\hline $\operatorname{IZC}(\mathrm{N})_{830}{ }^{\dagger}$ & 12 & 4.64 & 0.66 & 830 & 16 & 0.02 & 0.013 \\
\hline FAU $(\mathrm{TA})_{349}-\mathrm{IZC}_{259} \mathrm{D}$ & 13 & 1.45 & 0.22 & 259 & 76 & 0.29 & 0.064 \\
\hline $\mathrm{IZC}(\mathrm{A})_{278}$ & 12 & 1.55 & 0.22 & 278 & 77 & 0.28 & 0.062 \\
\hline $\operatorname{IZC}(\mathrm{N})_{305}$ & 12 & 1.7 & 0.24 & 305 & 116 & 0.38 & 0.091 \\
\hline $\operatorname{Am}(\mathrm{A})_{289}$ & 9 & 1.61 & 0.18 & 289 & 107 & 0.37 & 0.067 \\
\hline $\operatorname{Am}(N)_{289}$ & 10 & 1.61 & 0.19 & 289 & 94 & 0.33 & 0.063 \\
\hline \multirow{2}{*}{$\operatorname{Am}(\mathrm{N})_{512}$} & \multirow{2}{*}{13} & \multirow{2}{*}{2.86} & \multirow{2}{*}{0.42} & \multirow{2}{*}{512} & 68 & 0.13 & 0.055 \\
\hline & & & & & 55 & 0.11 & 0.044 \\
\hline $\operatorname{Am}(\mathrm{A})_{542}$ & 12 & 3.03 & 0.42 & 542 & 122 & 0.23 & 0.097 \\
\hline $\operatorname{Am}(\mathrm{A})_{776 \dagger}$ & 12 & 4.34 & 0.67 & 776 & 85 & 0.11 & 0.074 \\
\hline
\end{tabular}

${ }_{A}^{A}$ For the labeling of the preparations see methods 2.1.2. The dagger ( $\%$ symbol indicates non-fully crystalline CHA materials.

${ }^{B}$ Molar Si to Al ration in the obtained solids, assuming 100\% framework Si and Al (cfr. NMR evidence).

${ }^{C}$ Methanol from liquid extractions (see methods 2.3).

${ }^{D}$ The synthesis FAU(TA) ${ }_{349}-I Z C_{259}$ is explained in $S 2.2$. 


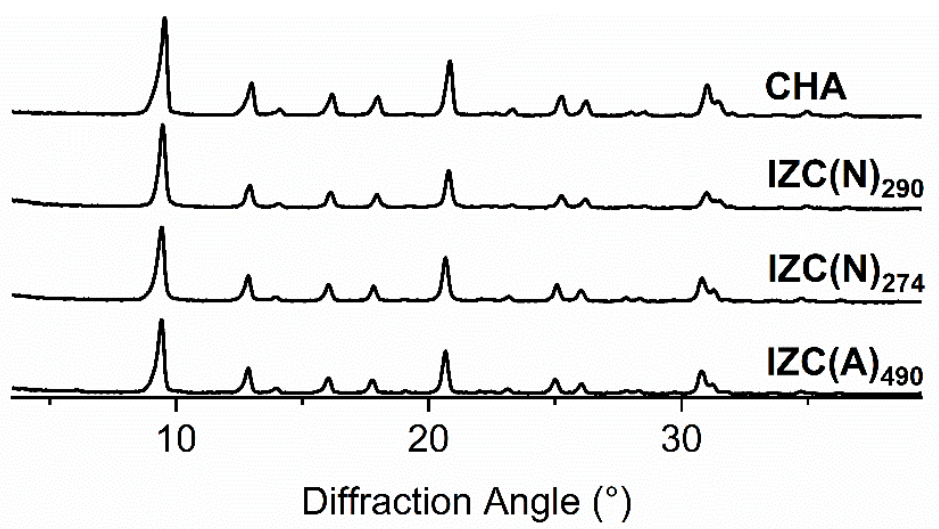

Figure S1: Powder X-ray (P-XRD) diffractograms of calcined CHA zeolites. CHA is the host material for post-synthetic Fe introduction (Section S1.1), the others are results of one-pot CHA preparations.

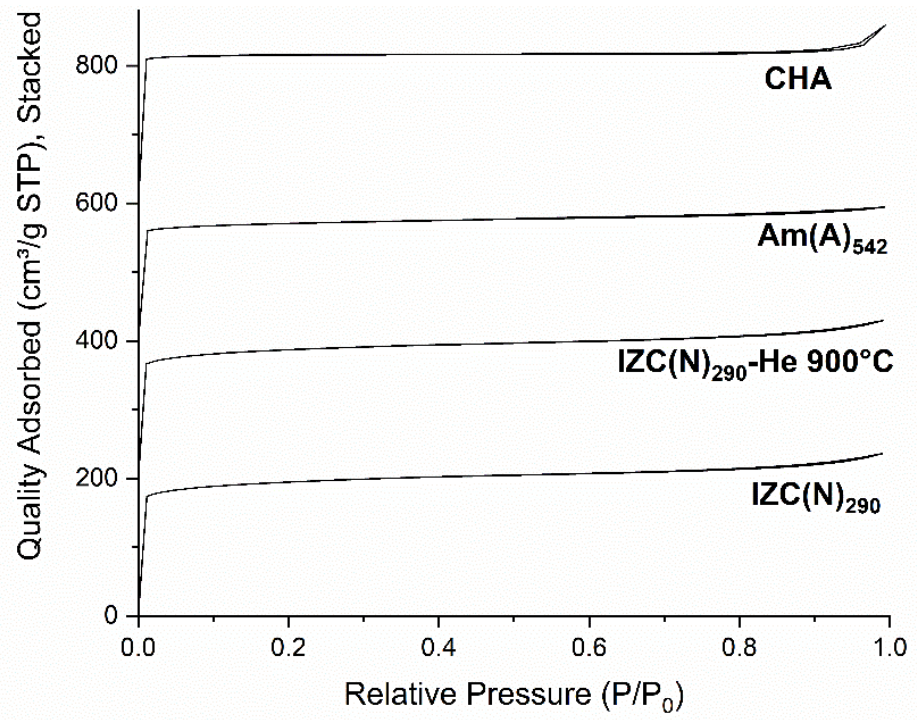

Figure S2: Nitrogen sorption isotherms of calcined SSZ-13 prepared with hydrothermal Fe. 'IZC $(\mathrm{N})_{290}-\mathrm{He} 900^{\circ} \mathrm{C}$ ' is measured after treatment in He at $900^{\circ} \mathrm{C}$ for 5 hours. Each isotherm is stacked by $200 \mathrm{~cm}^{3} / \mathrm{g}$. The t-plot microporosities are respectively $0.31,0.26$, 0.30 and $0.28 \mathrm{~cm}^{3} / \mathrm{g}$ for CHA (host material for post-synthetic Fe introduction), $\mathrm{Am}(\mathrm{A})_{542}, \operatorname{IZC}(\mathrm{N})_{290}-\mathrm{He} 900^{\circ} \mathrm{C}$ and $\operatorname{IZC}(\mathrm{N})_{290}$.

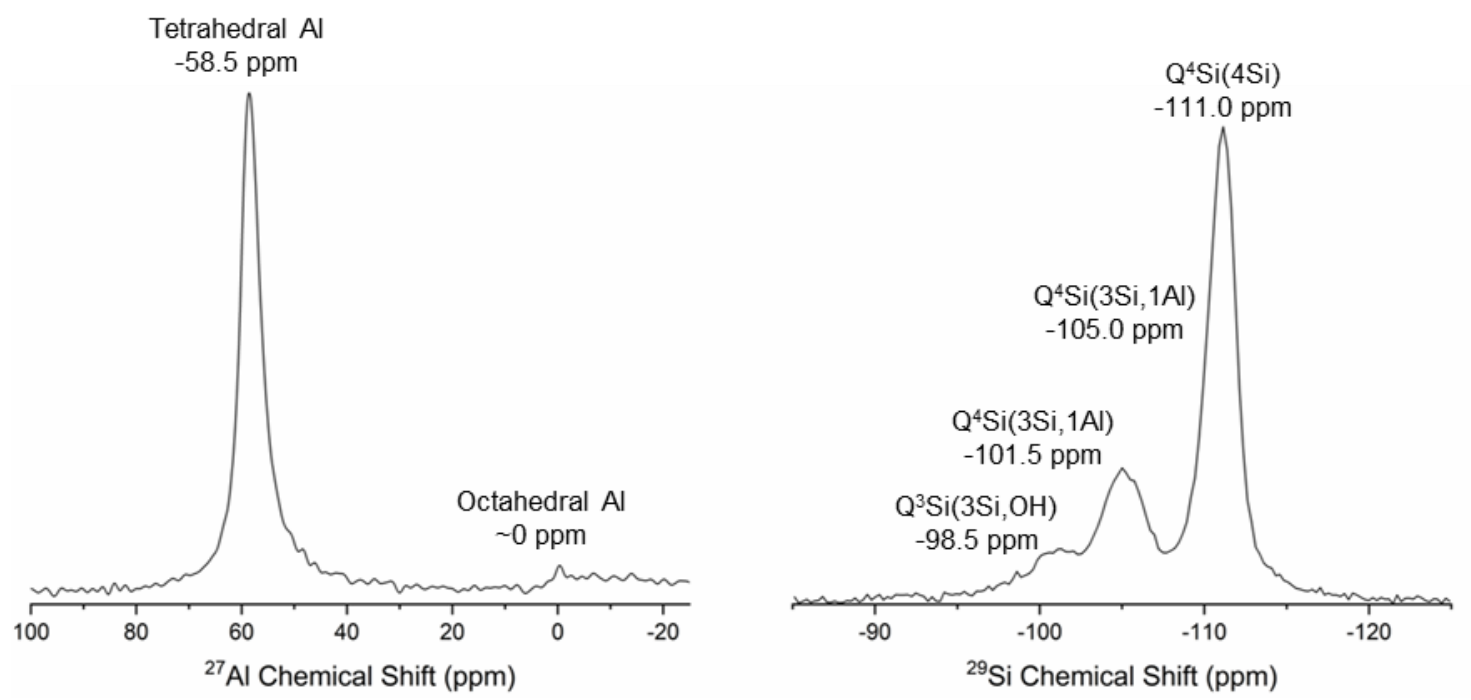

Figure S3: SS NMR of a calcined iron containing SSZ-13 from hydrothermal synthesis (FAU(TA) $349-I Z C)$. 

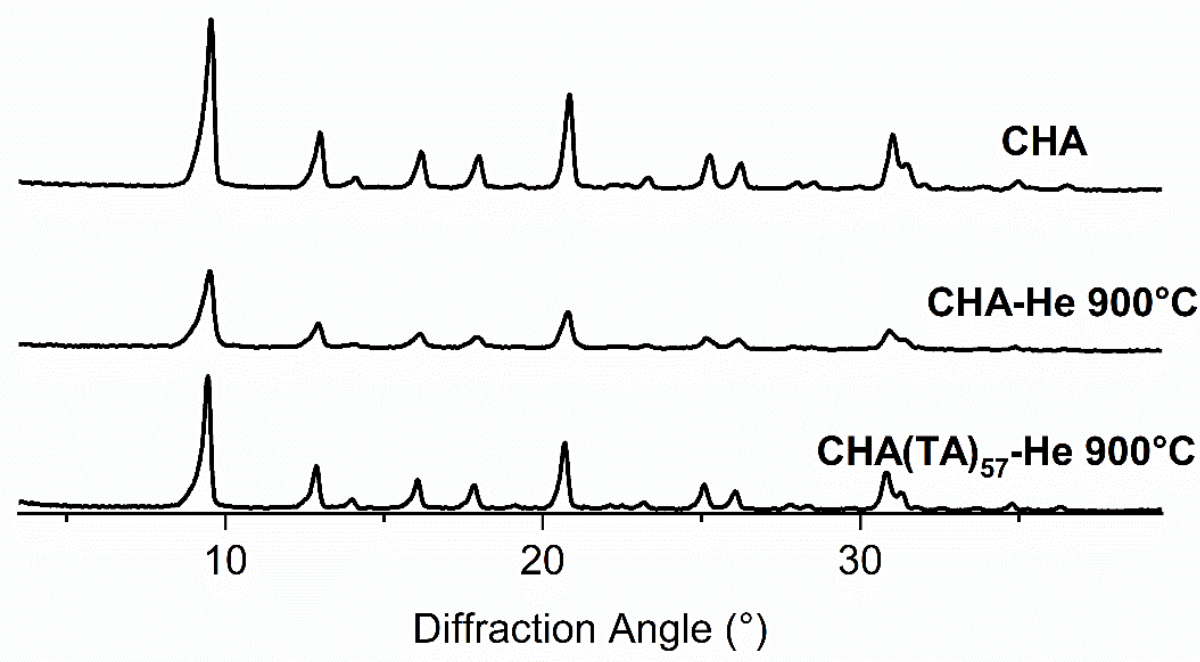

Figure S4: PXRD diffractograms to assess the stability of post-exchanged CHA preparations. Relative CHA-crystallinity loss due to a $900^{\circ} \mathrm{C}$ He treatment of CHA is $50 \%$, while only $31 \%$ using Fe-exchanged CHA $\left(\mathrm{CHA}(T A)_{57}\right)$.

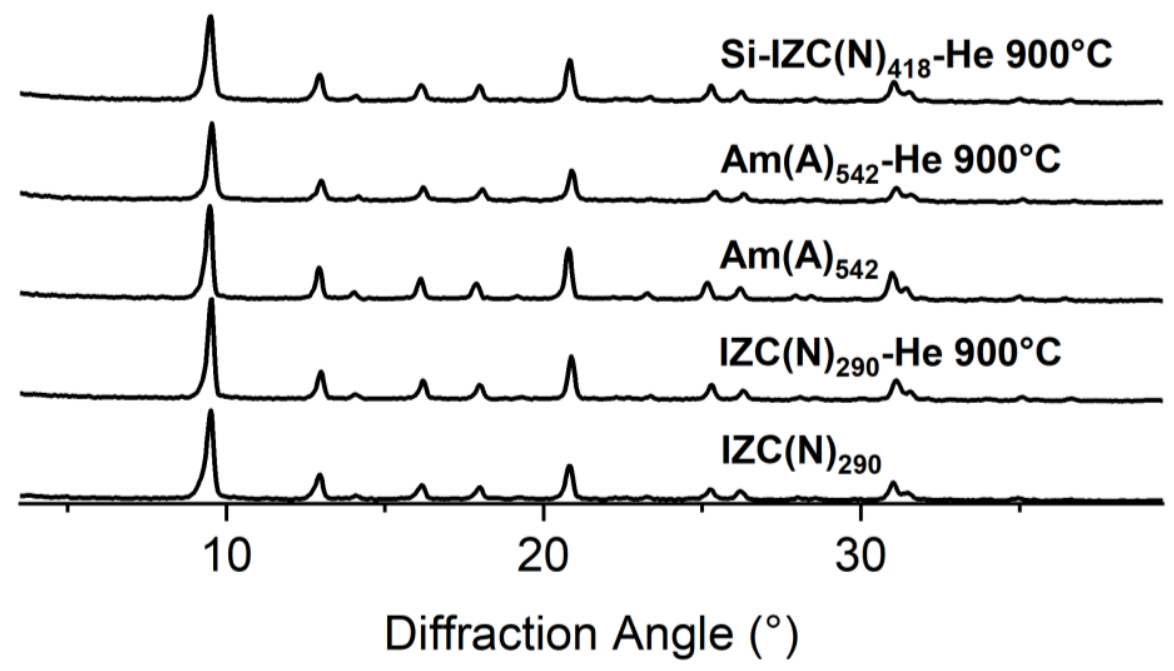

Figure S5: PXRD diffractograms of one-pot CHA preparations before and after He at $900^{\circ} \mathrm{C}$ (and further activation treatment, methods 2.2). Relative CHA-crystallinity loss due to the full activation cycle is respectively $32 \%$ and $17 \%$ for IZC(N) 290 and $\operatorname{Am}(A)_{542}$. 

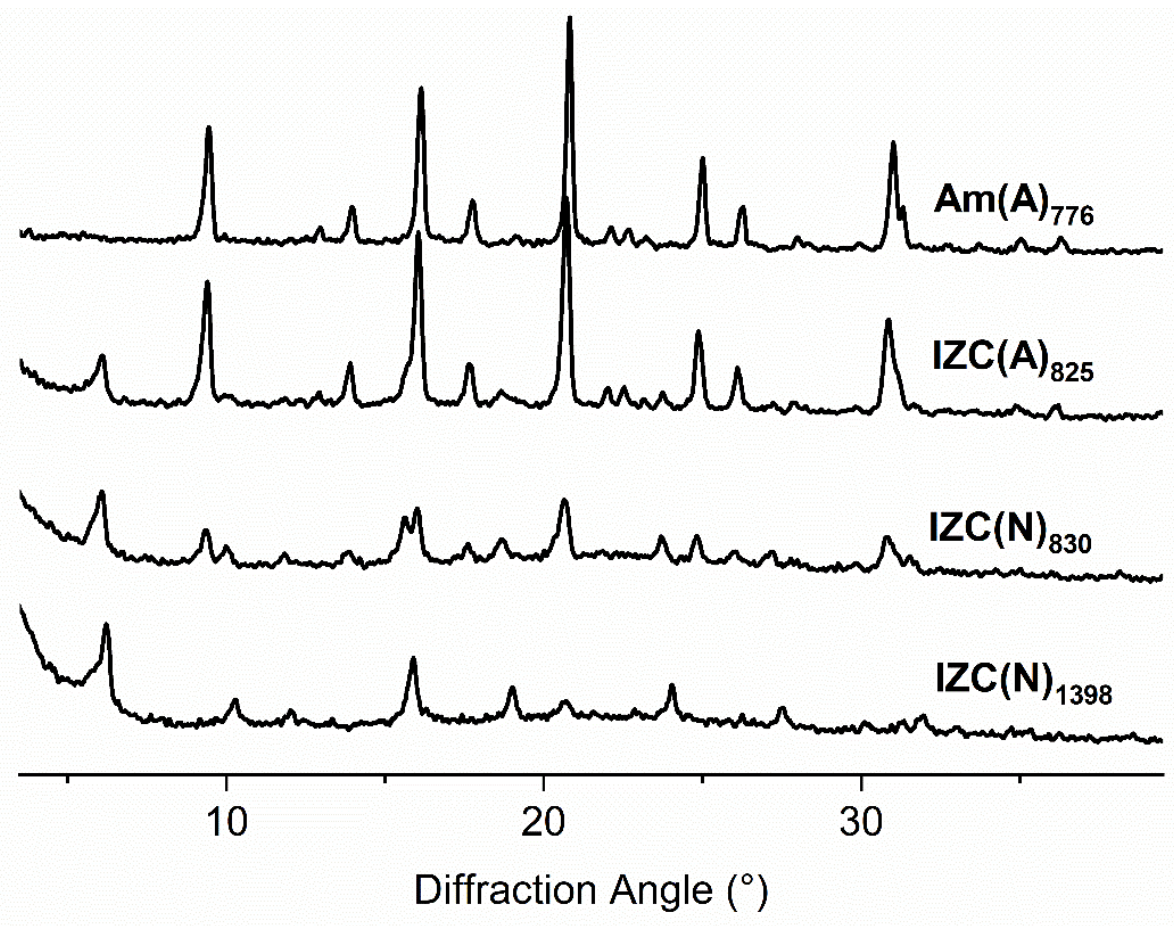

Figure S6: PXRD diffractograms of as-synthesized high Fe loading CHA preparations. CHA-crystallinity of Am(A) 776, IZC(A) 825 and $\operatorname{IZC}(N)_{830}$ are respectively $72 \%, 78 \%$ and $25 \%$ compared to $F A U(N)_{285}$. 

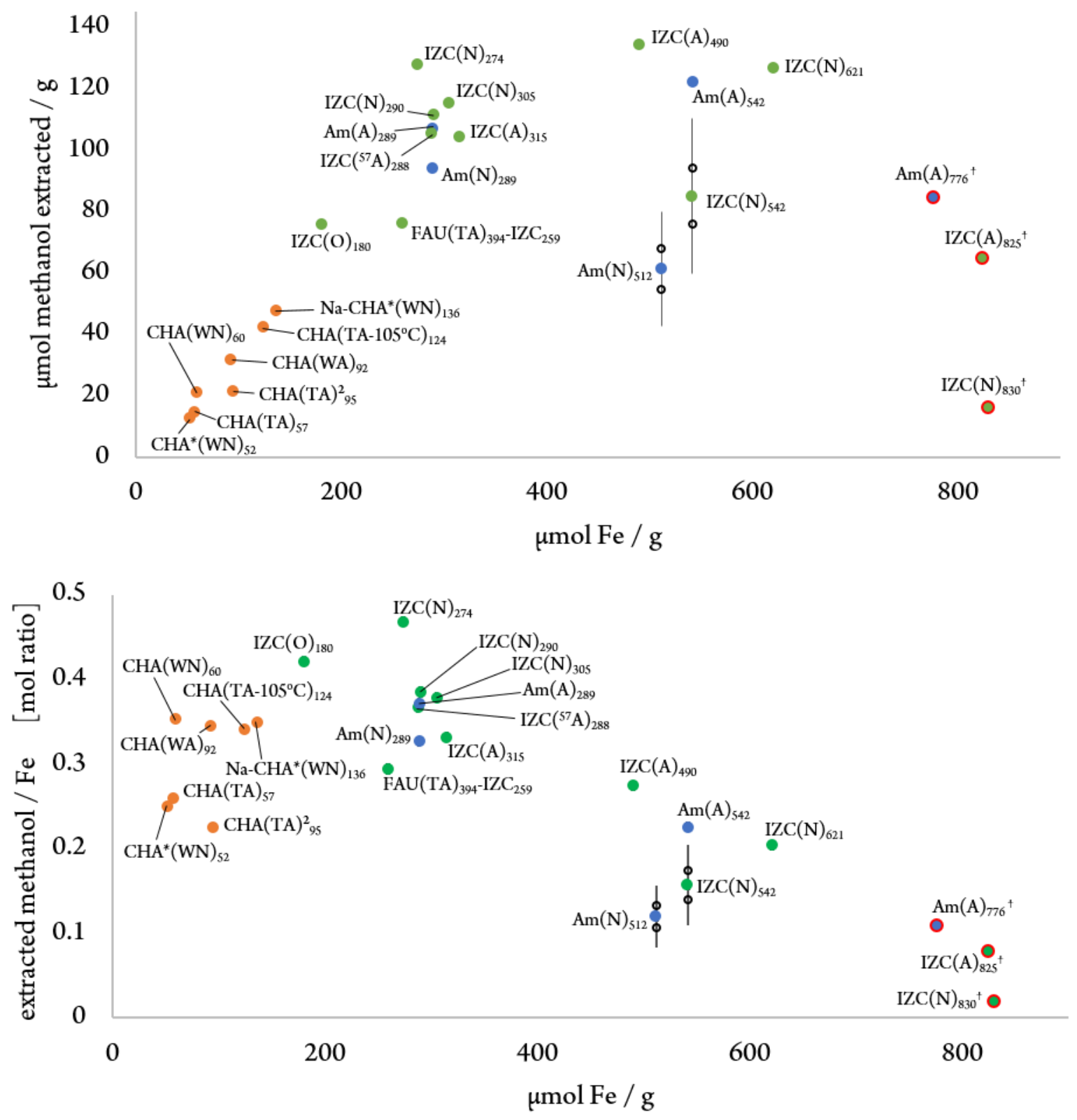

Figure S7: Labelled plots of figure 5 in the main text. 

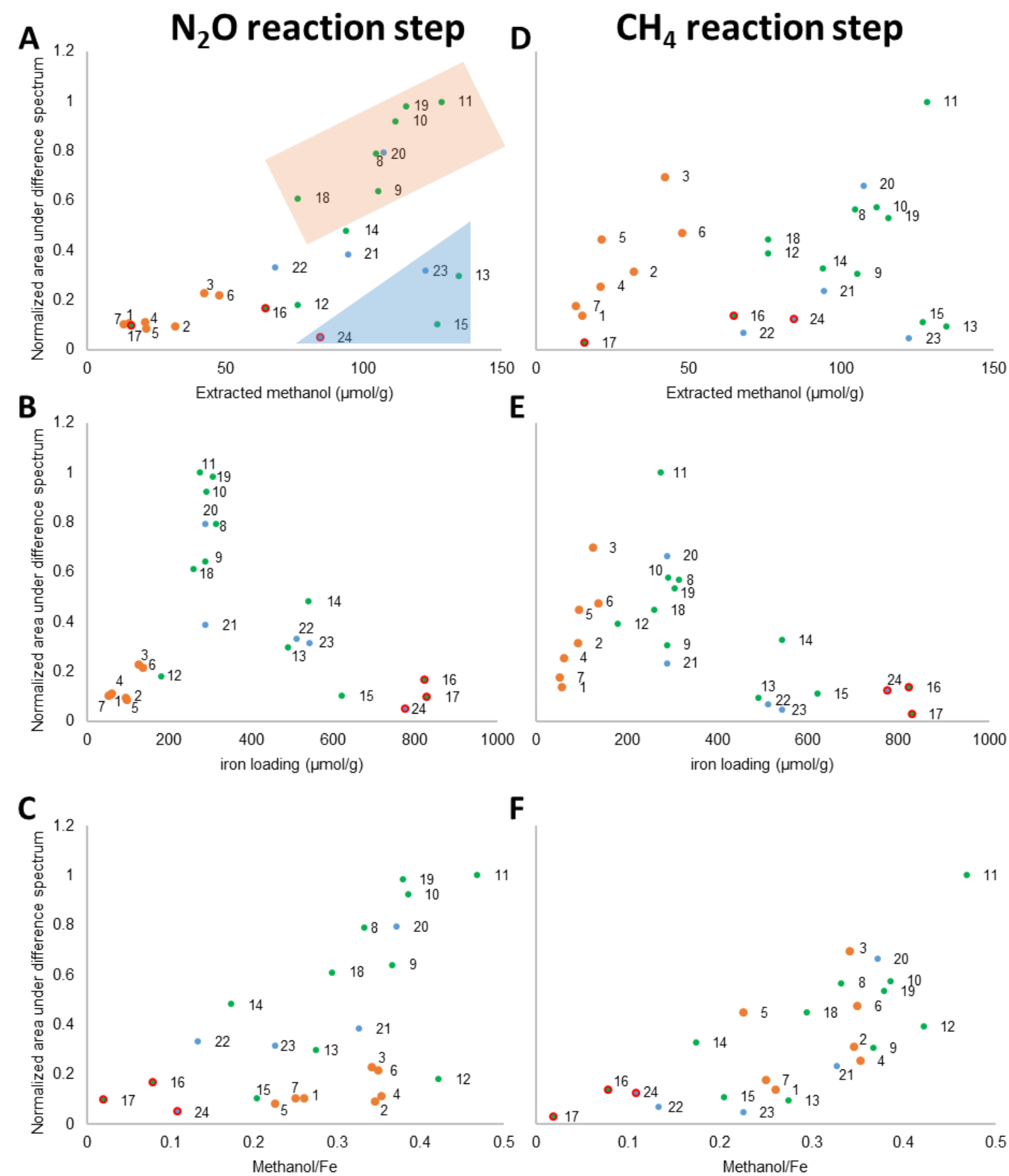

$\mathbf{F}$

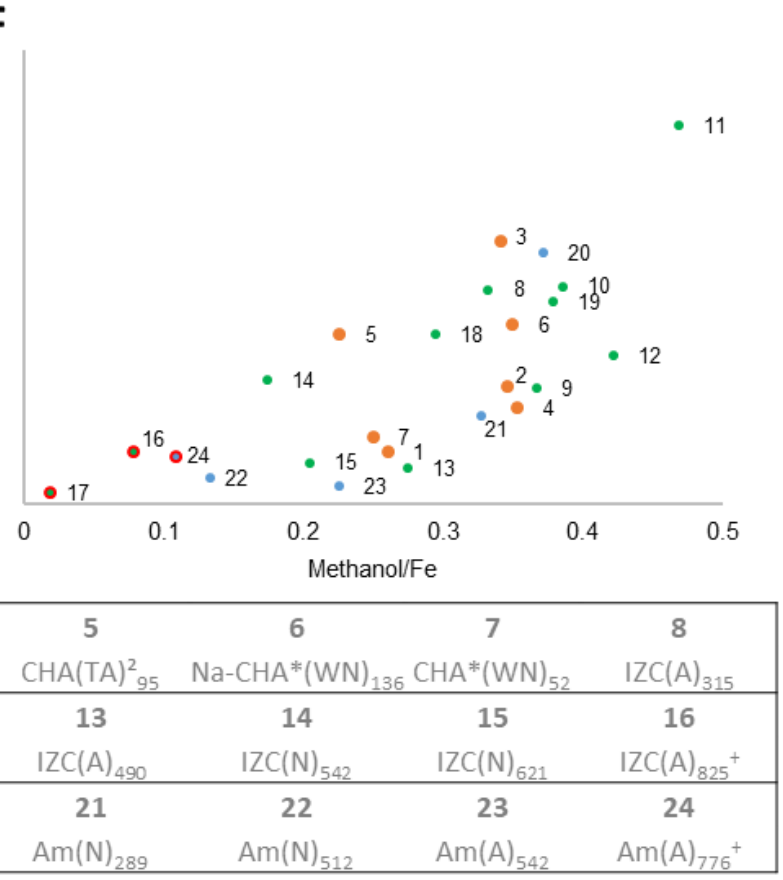

Figure S8: A-F - plots of the areas under the difference between Kubelka-Munk converted UV-Vis-NIR spectra before and after $\mathrm{N}_{2} \mathrm{O}$ reaction at $180^{\circ} \mathrm{C}(\mathrm{A}-\mathrm{C})$ or subsequent $\mathrm{CH}_{4}$ reaction at room temperature $(D-F)$. The area under the spectra from 5700 $15000 \mathrm{~cm}^{-1}$ was taken. Bottom table: samples corresponding to the numbers in the plots. 


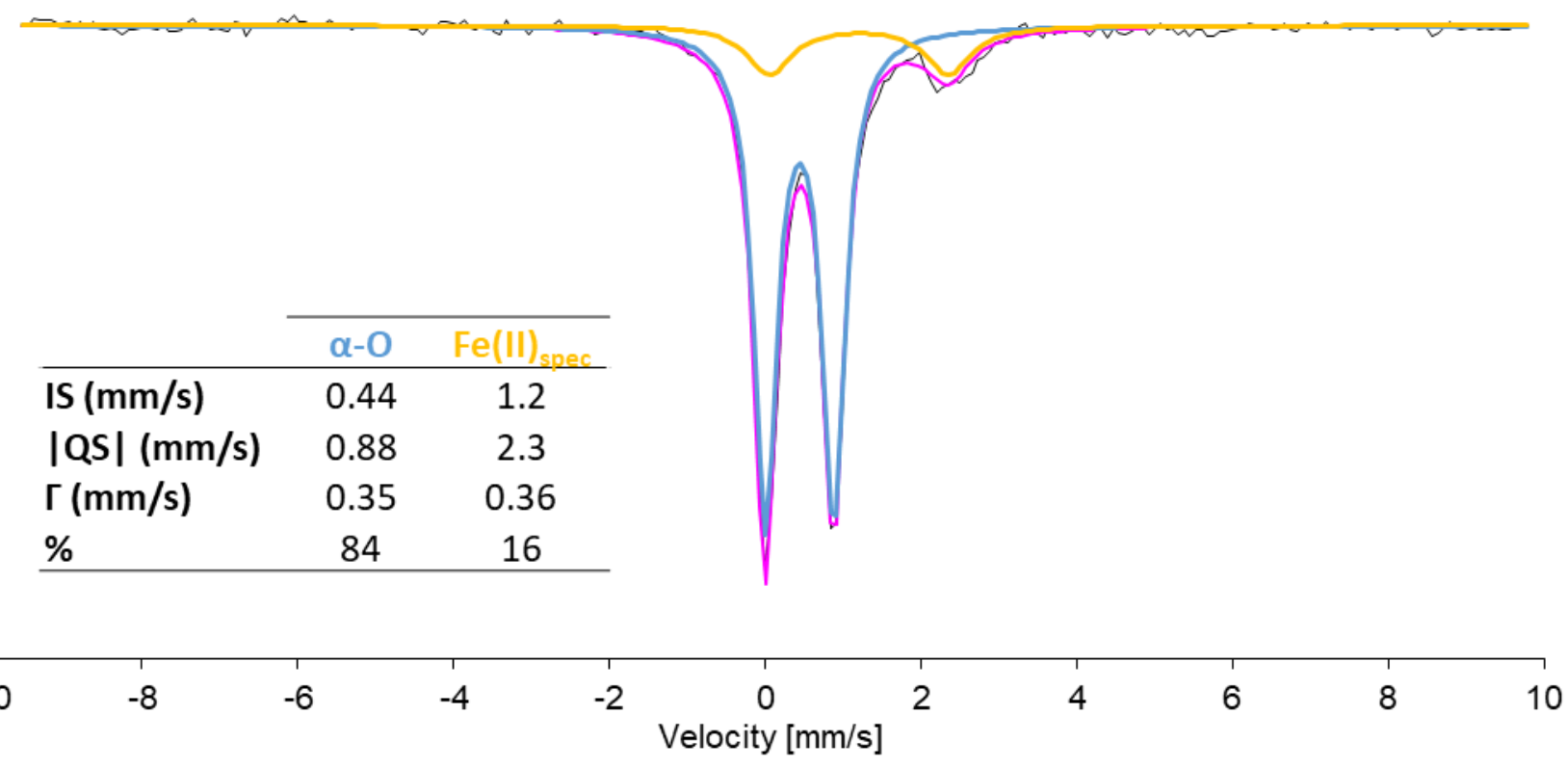

Figure S9: room temperature Mössbauer spectrum of $\mathrm{Fe}-\mathrm{CHA}$ with 0.3 wt.\% Fe and Si/Al=11 after the standard procedure up to heating in a $35 \% \mathrm{~N}_{2} \mathrm{O} / \mathrm{He}$ atmosphere for 25 minutes at $180^{\circ} \mathrm{C}$, with $84 \%$ of Fe as $\alpha-0$.

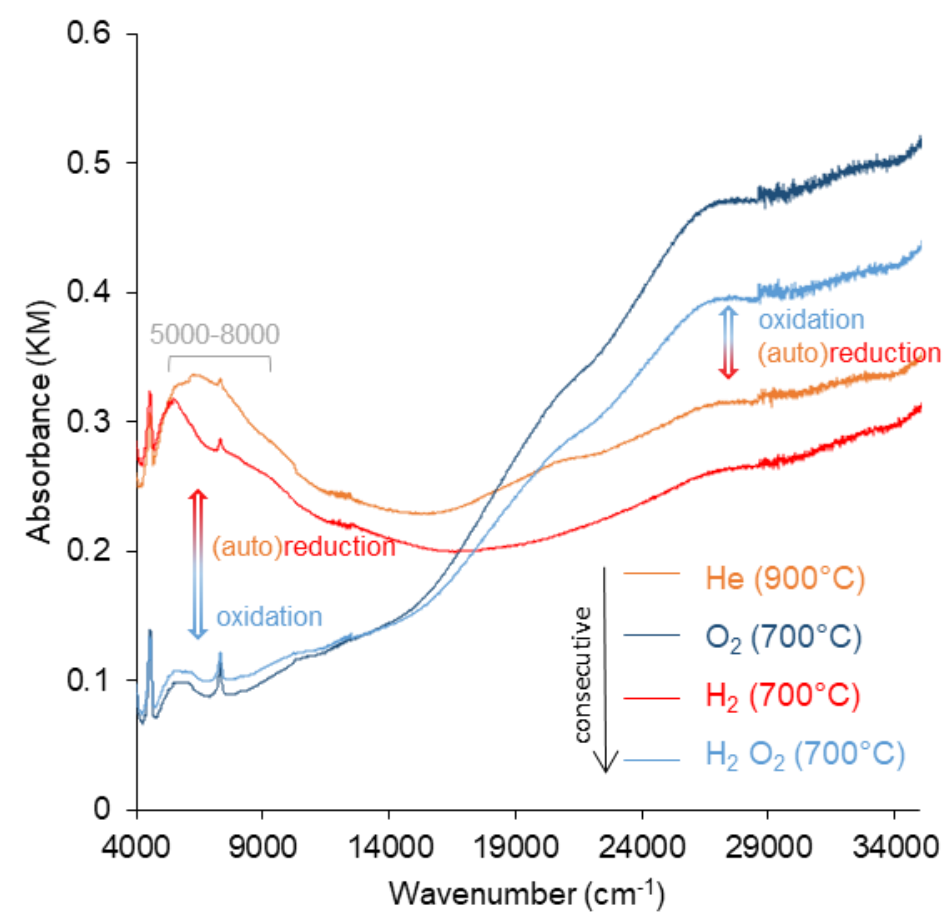

Figure S10: (auto)reduction and oxidation of spectator iron on $\mathrm{Am}(\mathrm{N})_{512}$ with $\mathrm{O}_{2}$ and $\mathrm{H}_{2}$ 

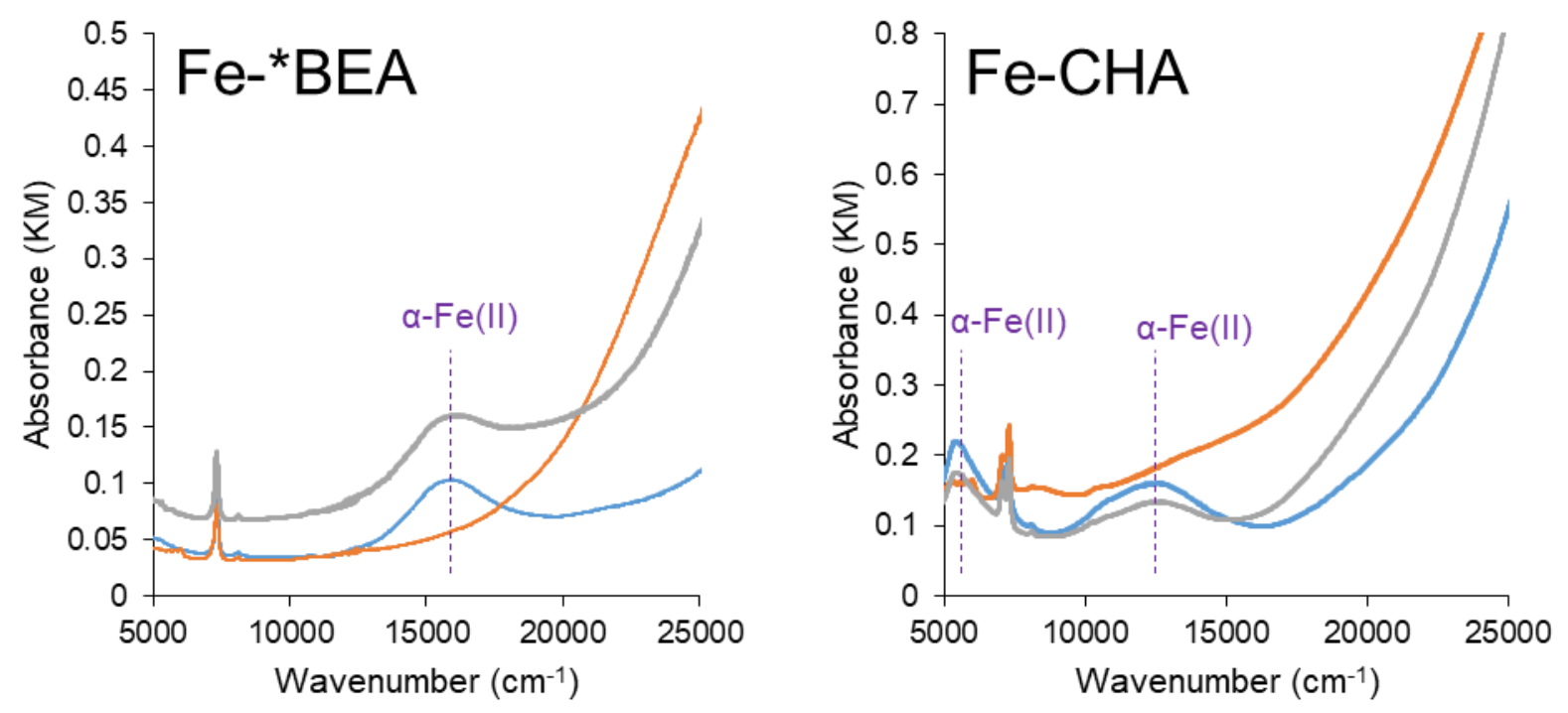

$\mathrm{He} 900^{\circ} \mathrm{C} \rightarrow \mathrm{N}_{2} \mathrm{O} / \mathrm{CH}_{4}$ reaction cycle $\rightarrow \mathrm{O}_{2} 650^{\circ} \mathrm{C}$

Figure S11: Recovery of $\alpha-\mathrm{Fe}(\mathrm{II})$ with activation in $\mathrm{O}_{2}$ at $650^{\circ} \mathrm{C}$. 

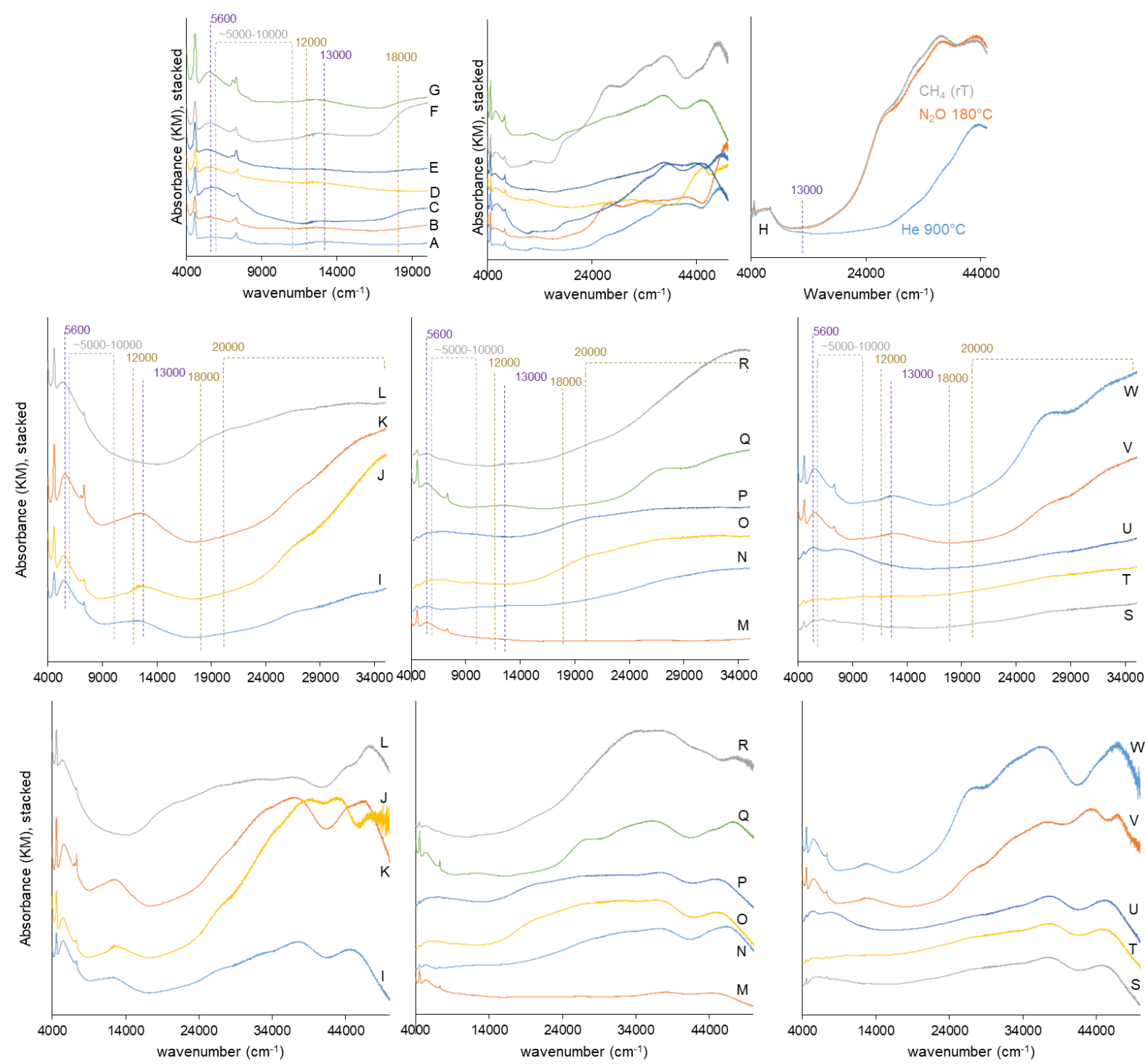

\begin{tabular}{|c|c|c|c|c|c|c|c|}
\hline A & B & c & D & E & $F$ & G & H \\
\hline $\mathrm{CHA}(\mathrm{TA})_{57}$ & $\mathrm{CHA}(\mathrm{WA})_{92}$ & $\mathrm{CHA}(\mathrm{TA})^{2}{ }_{95}$ & $\mathrm{CHA}(\mathrm{WN})_{60}$ & $\mathrm{CHA}^{\prime}(\mathrm{WN})_{60}$ & $\mathrm{CHA}\left(\mathrm{TA}-105^{\circ} \mathrm{C}\right)_{124}$ & $\mathrm{Na}-\mathrm{CHA}^{*}(\mathrm{WN})_{136}$ & $\mathrm{FAU}(\mathrm{TA})_{22}$ \\
\hline 1 & $\mathrm{~J}$ & K & $\mathbf{L}$ & M & $\mathbf{N}$ & 0 & $\mathbf{P}$ \\
\hline $\operatorname{IZC}(\mathrm{A})_{315}$ & $\mid Z C\left({ }^{57} A\right)_{288}$ & $\operatorname{IZC}(\mathrm{N})_{274}$ & $\operatorname{IZC}(0)_{180}$ & $\mathrm{IZC}(\mathrm{N})_{542}$ & $\operatorname{IZC}(A)_{490}$ & $\operatorname{IZC}(\mathrm{A})_{825}{ }^{+}$ & $\operatorname{IZC}(\mathrm{N})_{830^{+}}$ \\
\hline $\mathbf{Q}$ & $\mathbf{R}$ & s & $\mathbf{T}$ & U & $\mathrm{v}$ & w & \\
\hline $\mathrm{FAU}(\mathrm{TA})_{394}-\mathrm{IZC}_{259}$ & $\operatorname{IZC}(\mathrm{N})_{621}$ & $A m(N)_{512}$ & $\operatorname{Am}(A)_{542}$ & $A m(A)_{776}{ }^{+}$ & $\operatorname{Am}(N)_{289}$ & $\operatorname{Am}(A)_{289}$ & \\
\hline
\end{tabular}

Figure S12: in situ DR-UV-Vis-NIR spectra after $900^{\circ} \mathrm{C}$ treatment of all samples used in the study and their full energy range spectra. All spectra can be identified using the table at the bottom of the figure. At the top are the post-synthesis samples. In the middle and below are the one-pot preparations. 

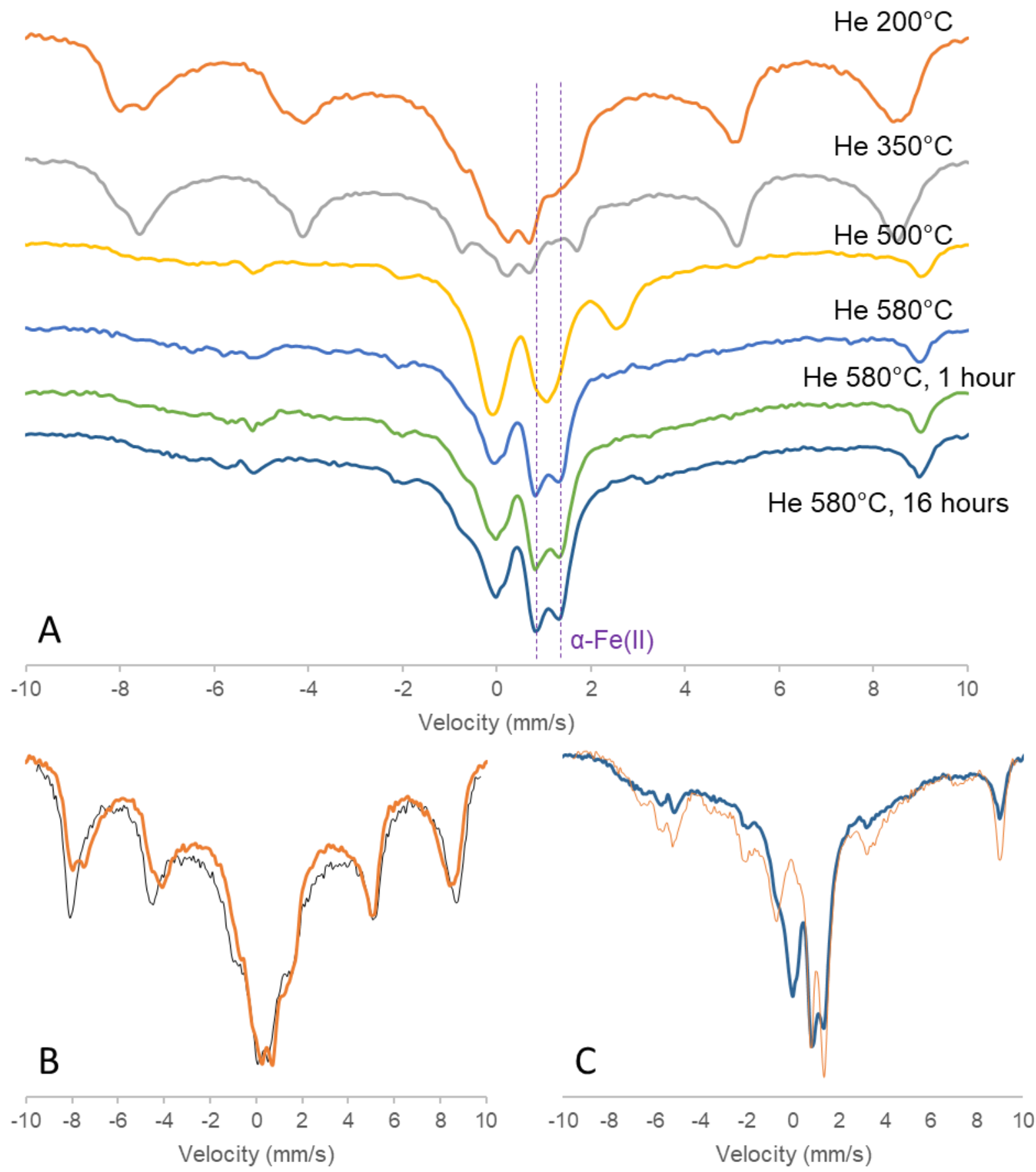

Figure S13: 6K Mössbauer spectra on a one-pot sample prepared from amorphous Al and Si sources and ${ }^{57} \mathrm{Fe}(\mathrm{acac})_{3}$ that was dried in helium at increasing temperatures (A). The sample dried at $200^{\circ} \mathrm{C}$ is compared to the IZC sample $($ IZC $(57 \mathrm{~A}) 288)$ spectrum after synthesis and dried at $100^{\circ} \mathrm{C}$ in (B). The sample dried at $580^{\circ} \mathrm{C}$ for 16 hours is compared to the IZC sample spectrum after $\mathrm{He} 650^{\circ} \mathrm{C}$ in (C). 

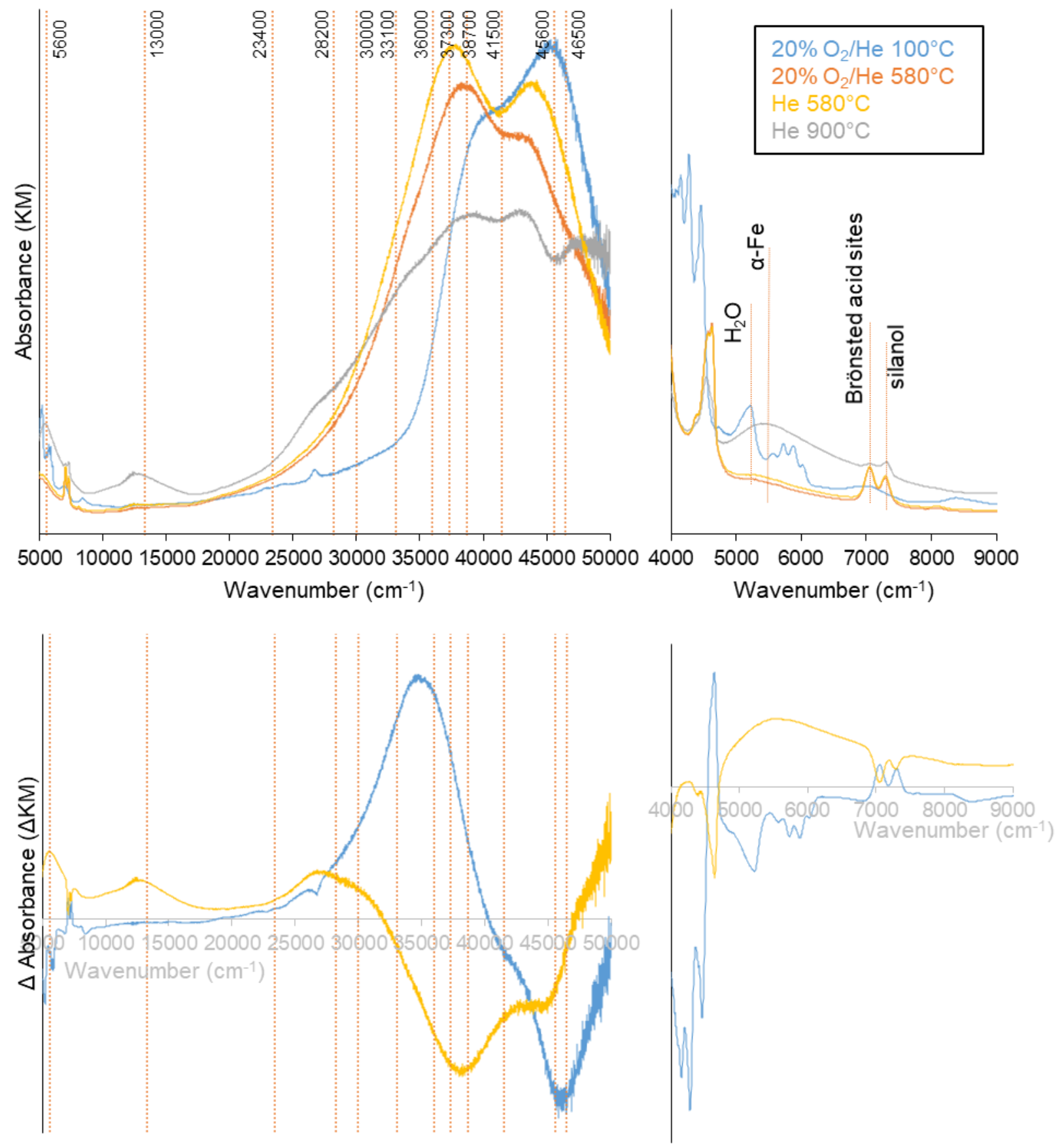

Figure S14: Top: DR-UV-Vi-NIR spectra of IZC $\left({ }^{57} \mathrm{~A}\right)_{288}$ after consecutive post-treatment steps with an enlargement of the NIR range to the right. Bottom: corresponding difference spectra. 

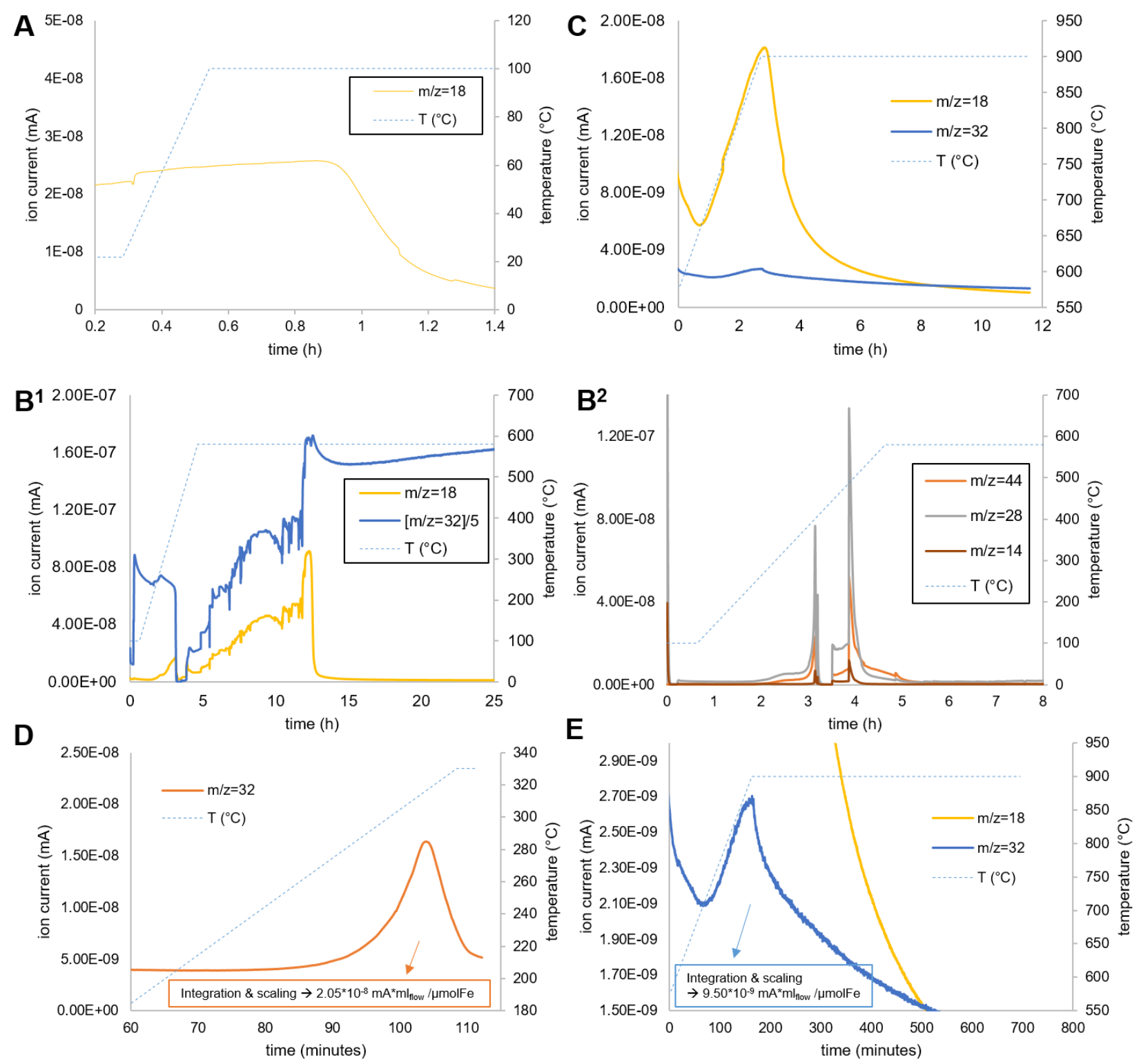

Figure S15: Mass spectra measured during drying $(A)$, calcination in $20 \% \mathrm{O}_{2} / \mathrm{He}\left(\mathrm{B}^{1}\right.$ and $\left.\mathrm{B}^{2}\right)$ and heating ramp to $900^{\circ} \mathrm{C}$ in helium (C) of IZC $\left({ }^{57} \mathrm{~A}\right)_{288}$. Mass spectrum measured during He TPD of IZC $\left({ }^{57} \mathrm{~A}\right)_{288}$ after $\mathrm{He} 900^{\circ} \mathrm{C}$ activation and activation of $\mathrm{N}_{2} \mathrm{O}$ in a $35 \% \mathrm{~N}_{2} \mathrm{O} / \mathrm{He}$ atmosphere for 25 minutes at $180^{\circ} \mathrm{C}(D)$. Enlargement of the oxygen desorption in panel $\mathrm{C}(\mathrm{E})$. For panel $D$ and $E$ the area under the peaks are calculated and corrected for the helium flow used and the amount of sample and its iron loading. 
A

\begin{tabular}{cccc}
\multicolumn{5}{c}{$\mathrm{He} 650^{\circ} \mathbf{C}$} \\
Title & alpha Fe & $\begin{array}{c}\mathrm{Fe}(\mathrm{III}) \\
\text { doublet }\end{array}$ & $\mathrm{Fe}$ (III) hyperfine \\
\hline IS & 1.08 & 0.28 & 0.28 \\
QS & 0.63 & 1.9 & 1.9 \\
$\%$ & 12 & 19 & 69 \\
D & & & -0.8 \\
E/D & & & 0.3 \\
\hline
\end{tabular}
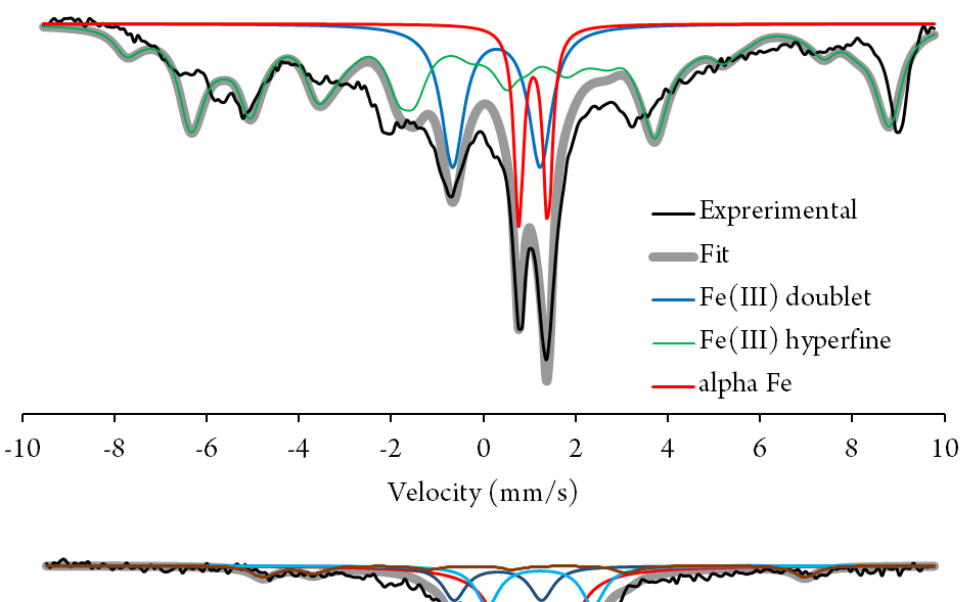

B

\begin{tabular}{ccccc}
\multicolumn{5}{c}{$\mathrm{He} 900^{\circ} \mathbf{C}$} \\
\hline Title & alpha Fe & $\begin{array}{c}\mathrm{Fe}(\mathrm{III}) \\
\text { doublet }\end{array}$ & $\begin{array}{c}\mathrm{Fe}(\mathrm{II}) \\
\text { spectator }\end{array}$ & $\begin{array}{c}\mathrm{Fe}(\mathrm{III}) \\
\text { spectator }\end{array}$ \\
\hline IS & 1.08 & 0.28 & 1.2 & 0.37 \\
QS & 0.63 & 1.9 & 2.3 & 1.4 \\
$\%$ & 72 & 9 & 12 & 7 \\
B & & & & 36.5 \\
\hline
\end{tabular}

_Exprerimental

Simulation

—alpha- $\mathrm{Fe}$

- Fe(III) doublet

- Fe(II) spectator

- Fe(III) spectator

\begin{tabular}{ccccccccccc}
\hline-10 & -8 & -6 & -4 & -2 & 0 & 2 & 4 & 6 & 8 & 10 \\
& & & & &
\end{tabular}

C

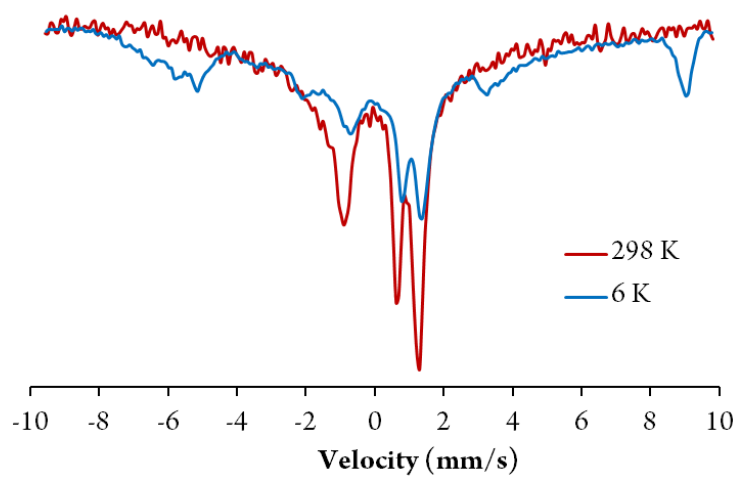

Figure S16: $6 \mathrm{~K}$ Mössbauer spectra and deconvoluted contributions of $\operatorname{IZC}\left({ }^{57} \mathrm{~A}\right)_{288}$ after $\mathrm{He} 650^{\circ} \mathrm{C}(\mathrm{A})$ and after $\mathrm{He} 900^{\circ} \mathrm{C}(\mathrm{B})$. C) $6 \mathrm{~K}$ (blue) and $298 \mathrm{~K}$ (red) Mössbauer spectra of IZC $\left({ }^{57} \mathrm{~A}\right)_{288}$ after He $650^{\circ} \mathrm{C}$. At $298 \mathrm{~K}$ the Fe(III) hyperfine collapses into a doublet. 


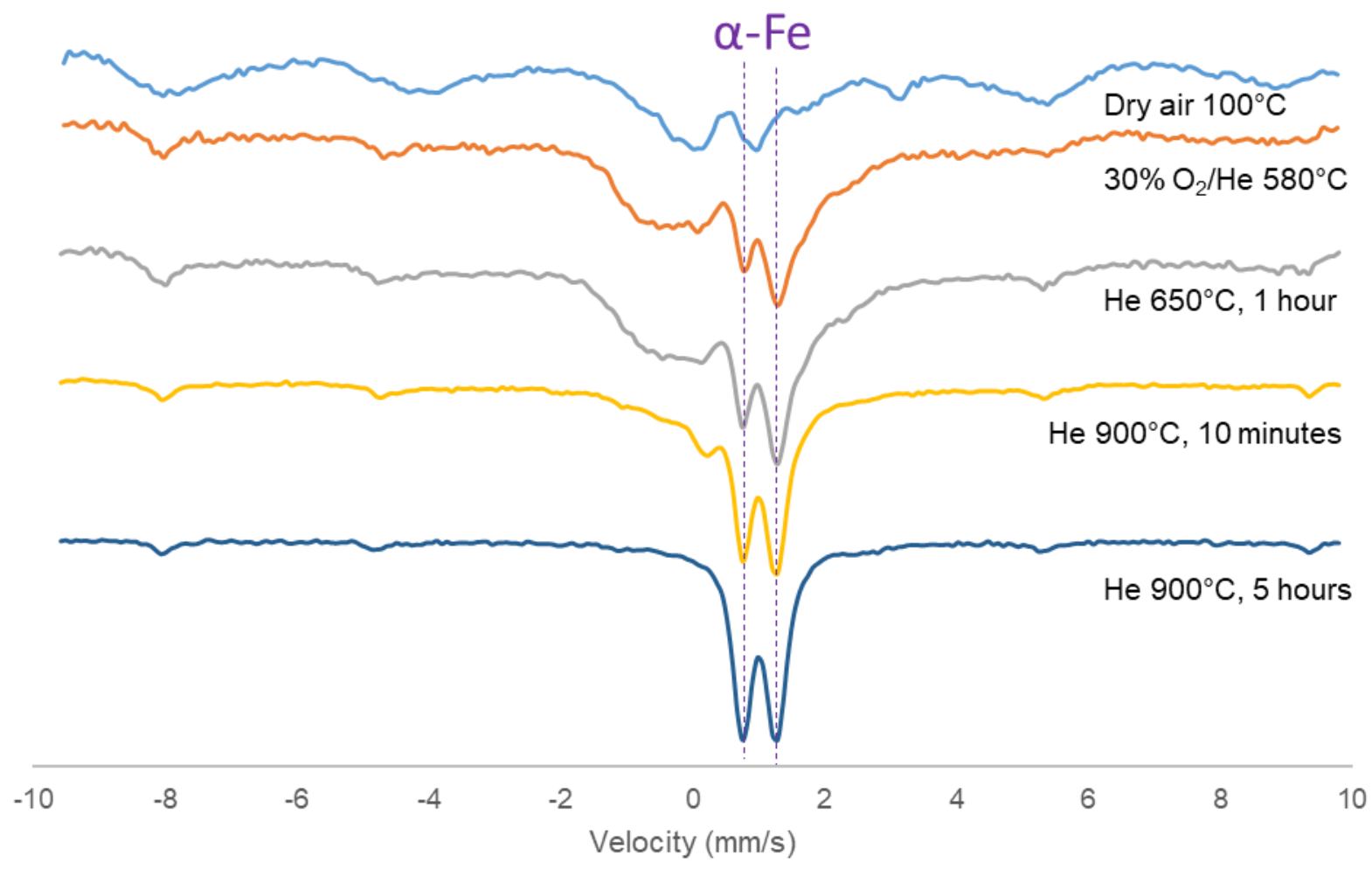

Figure S17: $6 \mathrm{~K}$ Mössbauer spectra of $100 \% 57 \mathrm{Fe}-{ }^{\star} \mathrm{BEA}, 0.30$ wt.\% $\mathrm{Fe}, \mathrm{Si} / \mathrm{Al}=12.5$, prepared from $\mathrm{H}-{ }^{\star} \mathrm{BEA}+{ }^{57} \mathrm{Fe}(\mathrm{acac})_{3}$ in toluene and then post treated with consecutive steps as indicated. 

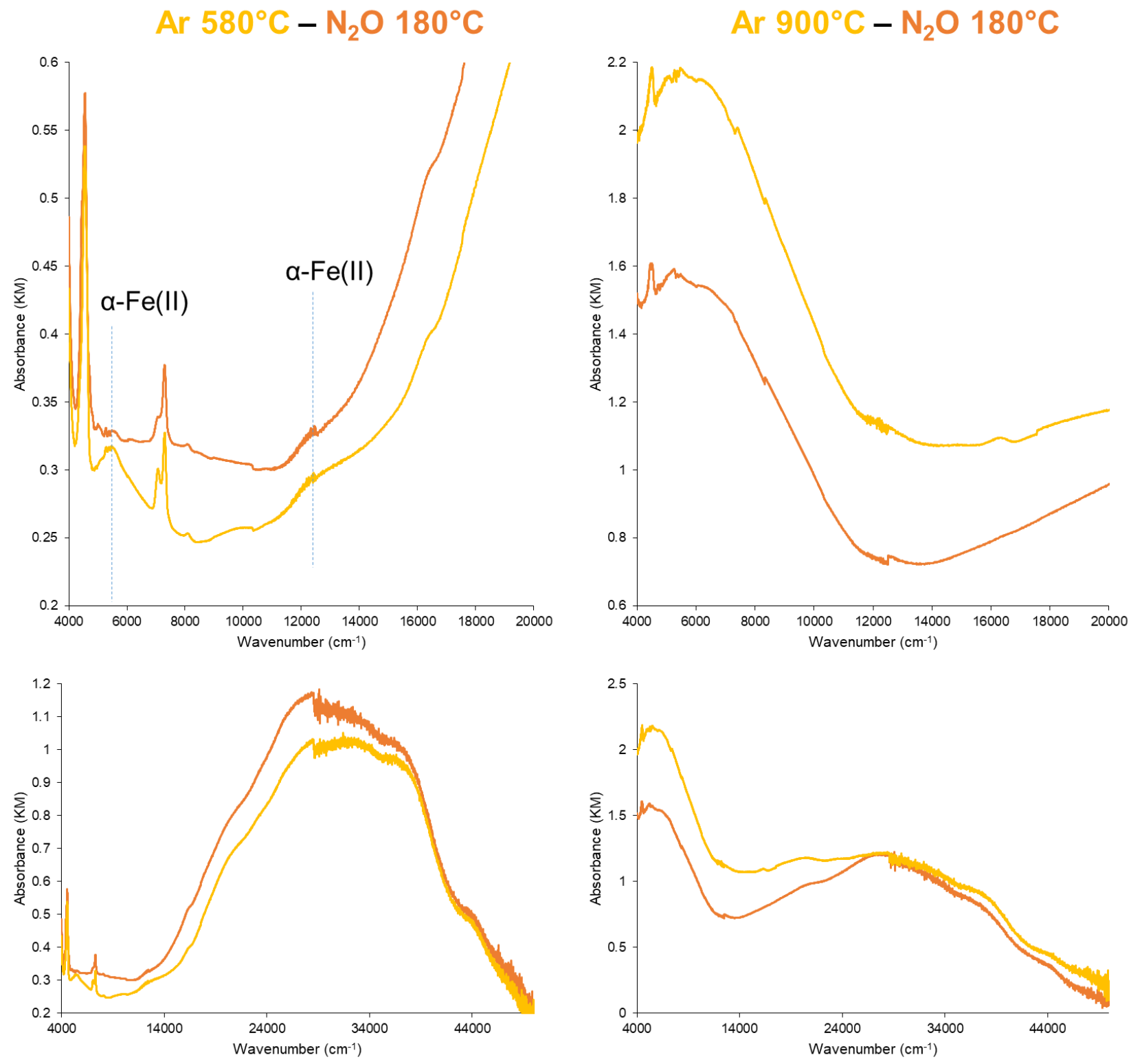

Figure S18: DR-UV-Vis-NIR spectra of IZC+Na(N) 540 after argon treatment at $580^{\circ} \mathrm{C}$ (left) or $900^{\circ} \mathrm{C}$ (right) followed by $\mathrm{N}_{2} \mathrm{O}$ treatment for 25 minutes at $180^{\circ} \mathrm{C}$ in a $35 \% \mathrm{~N} 2 \mathrm{O} / \mathrm{He}$ atmosphere. The spectra after argon are in yellow, after $\mathrm{N}_{2} \mathrm{O}$ in orange. Full range spectra are shown below spectra zooming into the 4000 to $20000 \mathrm{~cm}^{-1}$ energy range. 


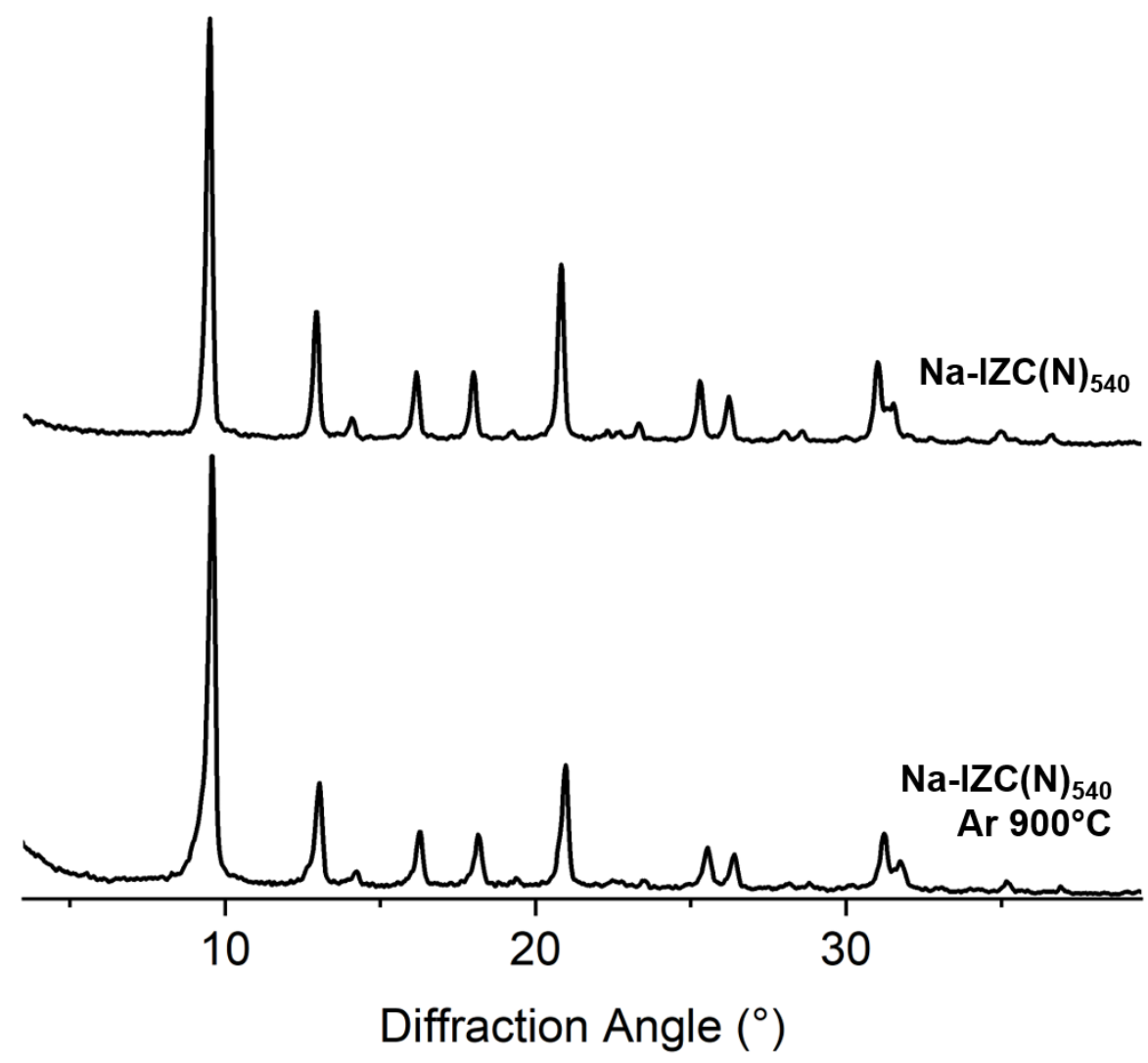

Figure S19: X-ray diffractograms of a calcined 'Na-IZC(N)540' (top) preparation before (top) and after Argon $900^{\circ} \mathrm{C}$ treatment (bottom).

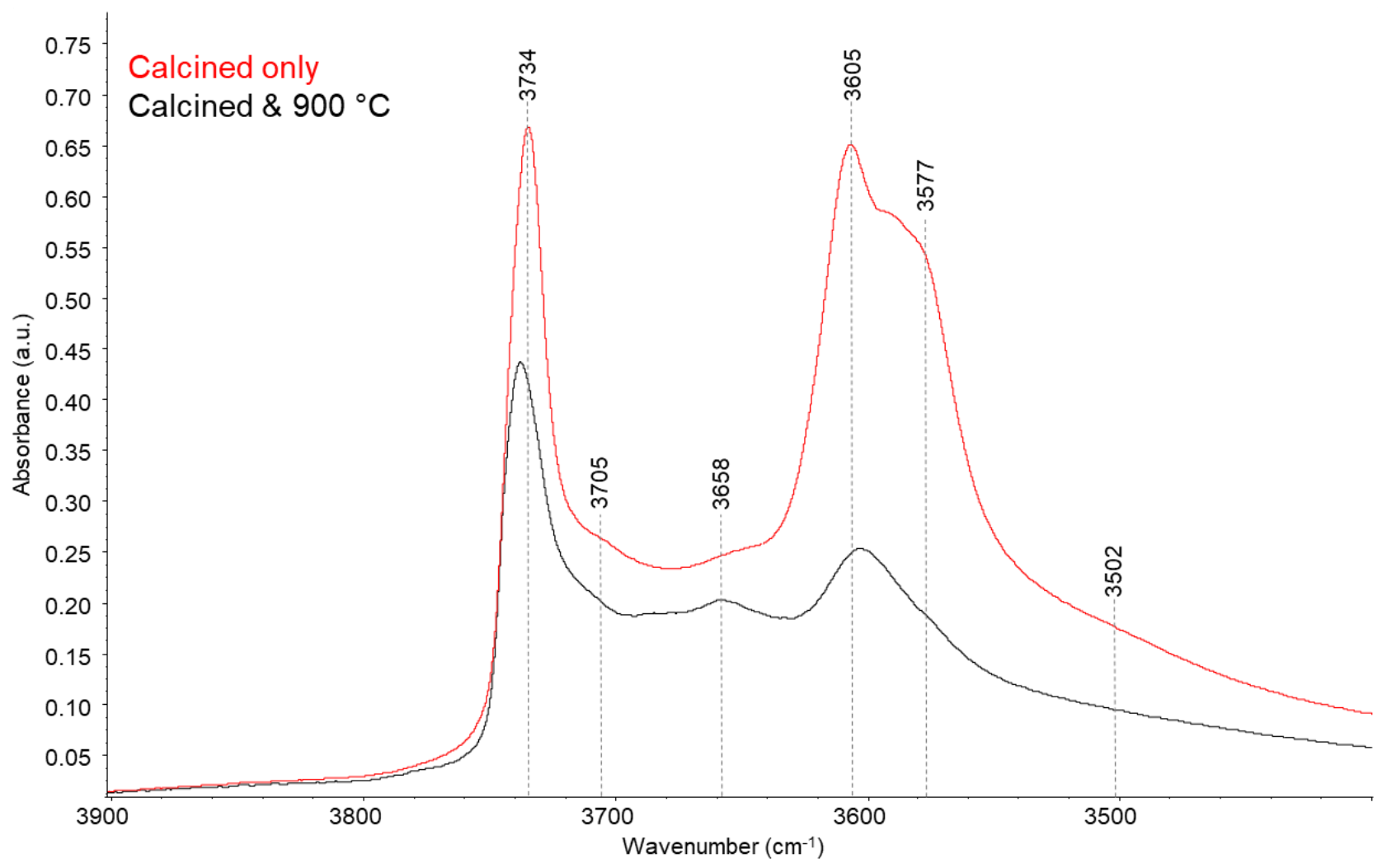

Figure S20: $\mathrm{OH}$ stretch region of the FT-IR spectra of calcined IZC $\left({ }^{57} \mathrm{~A}\right) 288$ before (red) and after (black) treatment at $900^{\circ} \mathrm{C}$. 


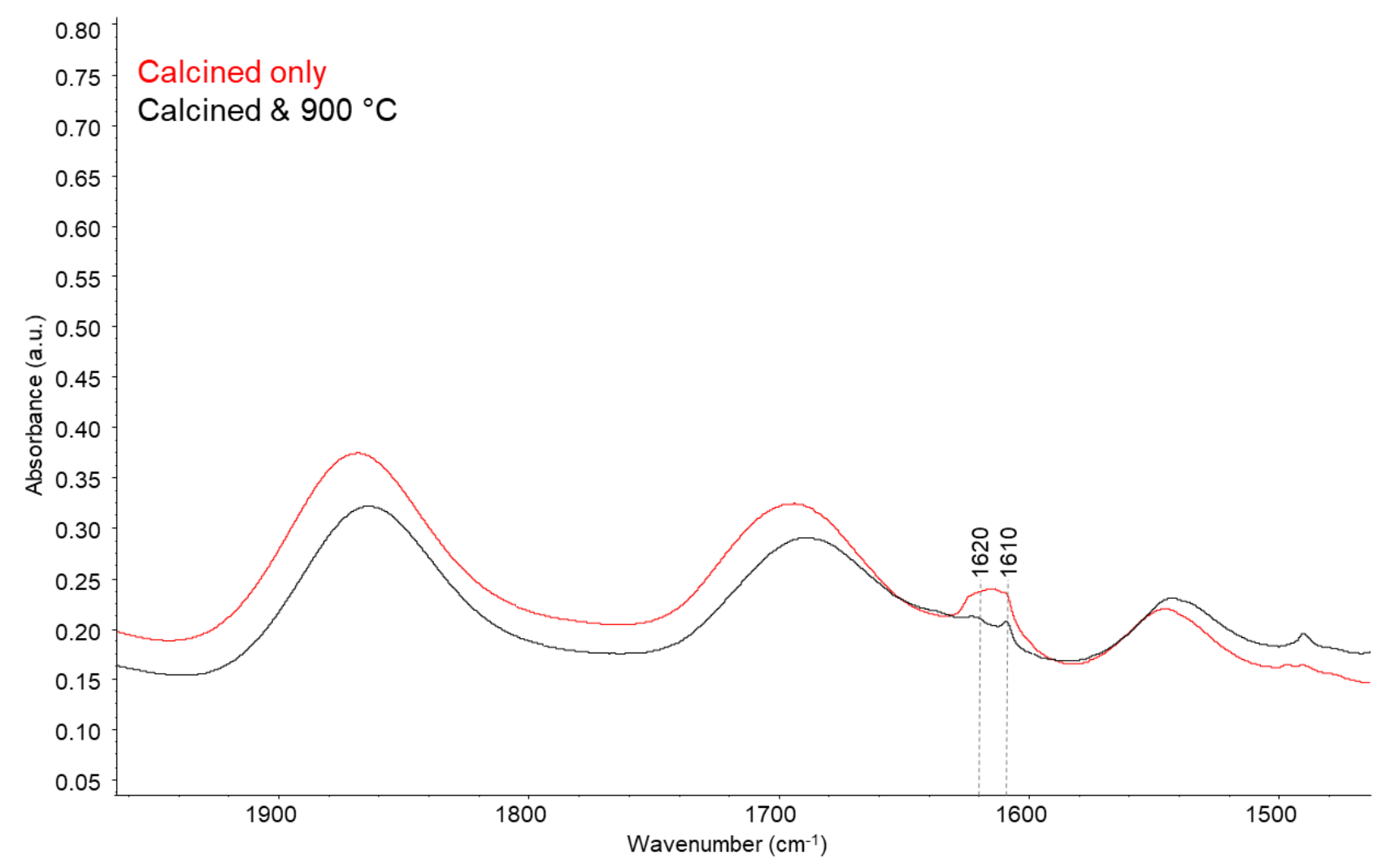

Figure S21: 2000 - $1500 \mathrm{~cm}^{-1}$ region of the FT-IR spectra of calcined IZC $(57 \mathrm{~A})_{288}$ before (red) and after (black) treatment at $900^{\circ} \mathrm{C}$.

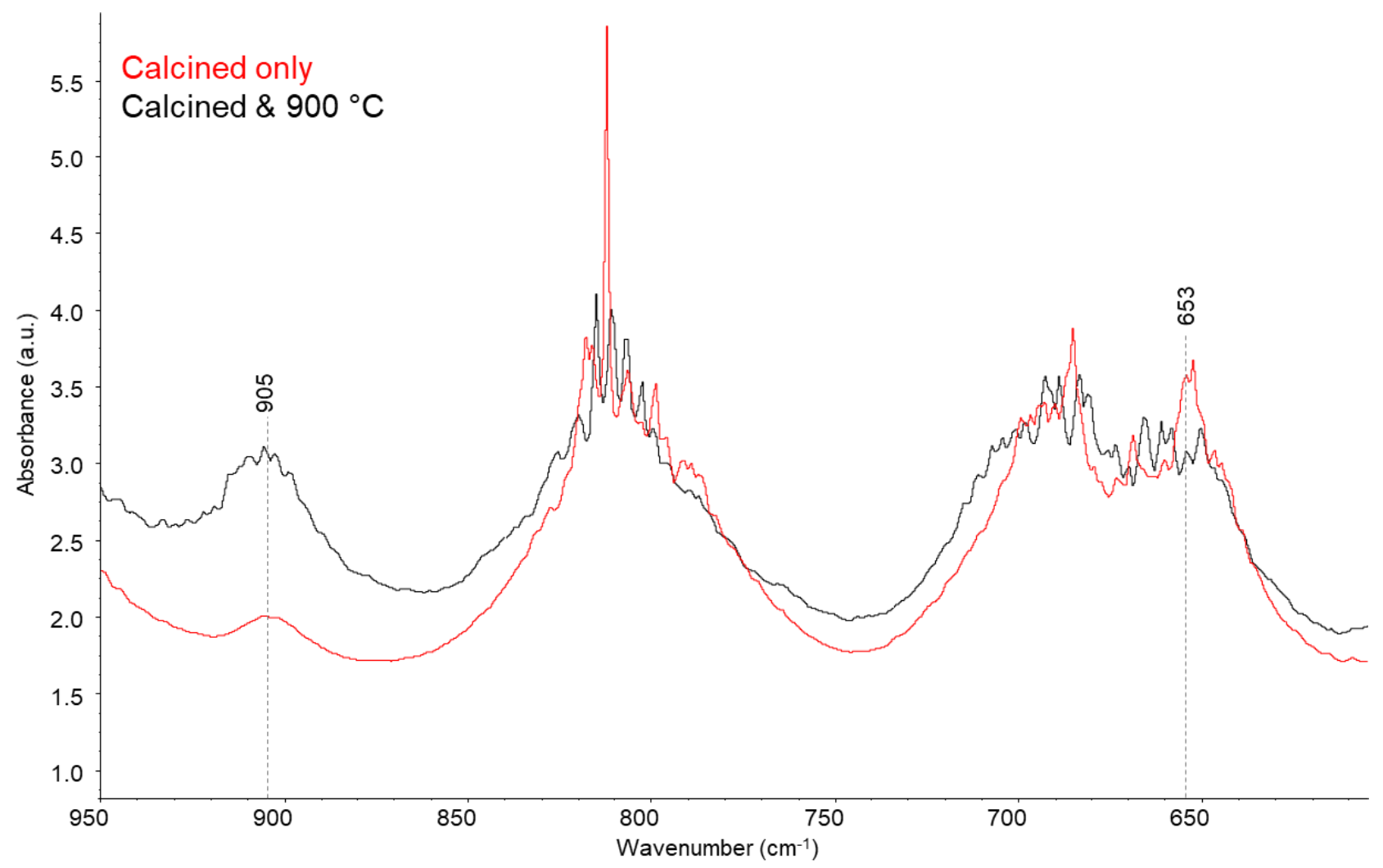

Figure S22: framework fundamental vibrations region of the FT-IR spectra of calcined IZC $\left({ }^{57} A\right)_{288}$ before (red) and after (black) treatment at $900^{\circ} \mathrm{C}$. 


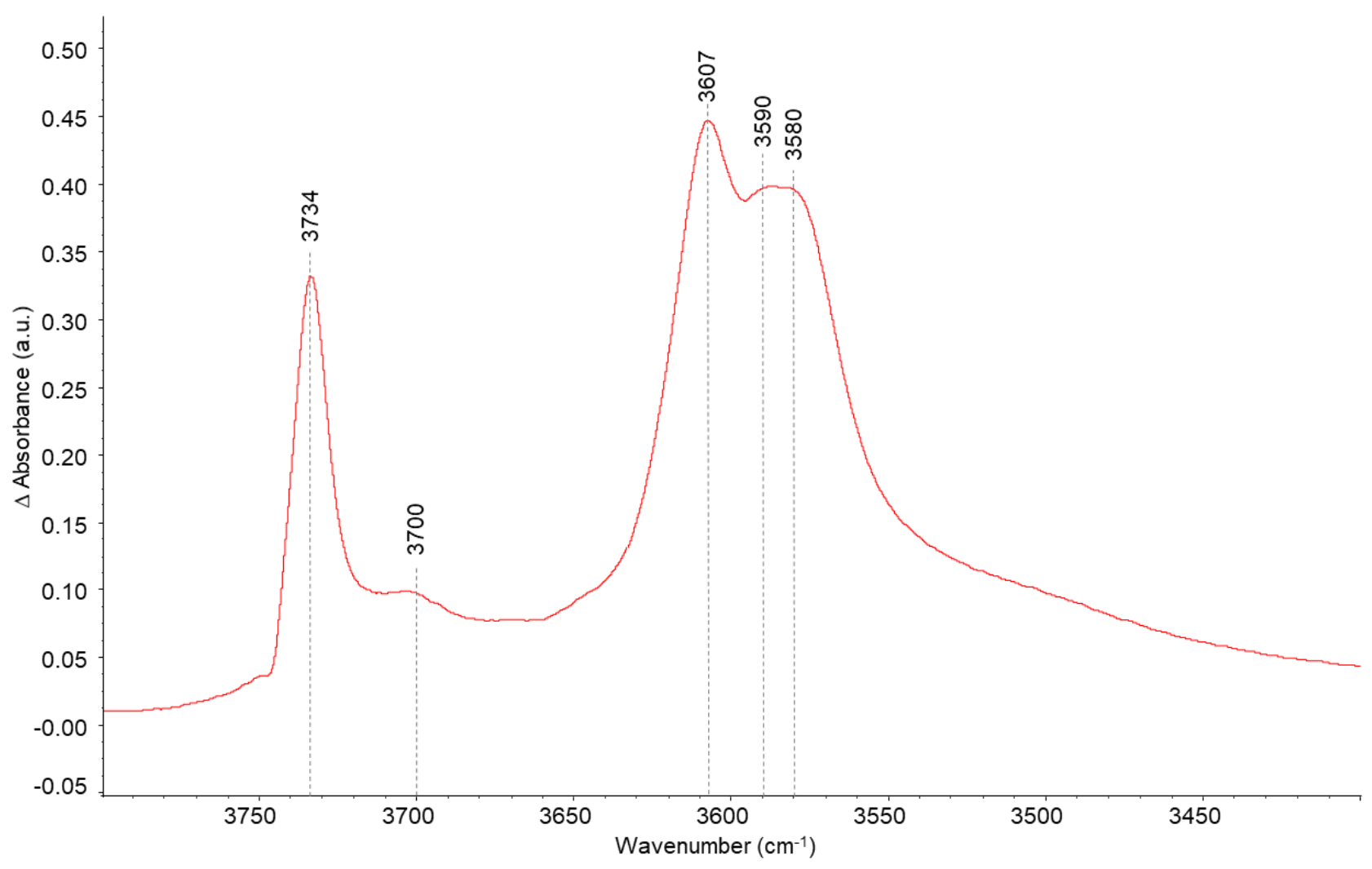

Figure S23: Difference FT-IR spectrum in the $\mathrm{OH}$ stretch region of calcined IZC $\left({ }^{57} \mathrm{~A}\right)_{288}$ subtracting the spectrum after $900{ }^{\circ} \mathrm{C}$ treatment from the spectrum before $900{ }^{\circ} \mathrm{C}$ treatment.

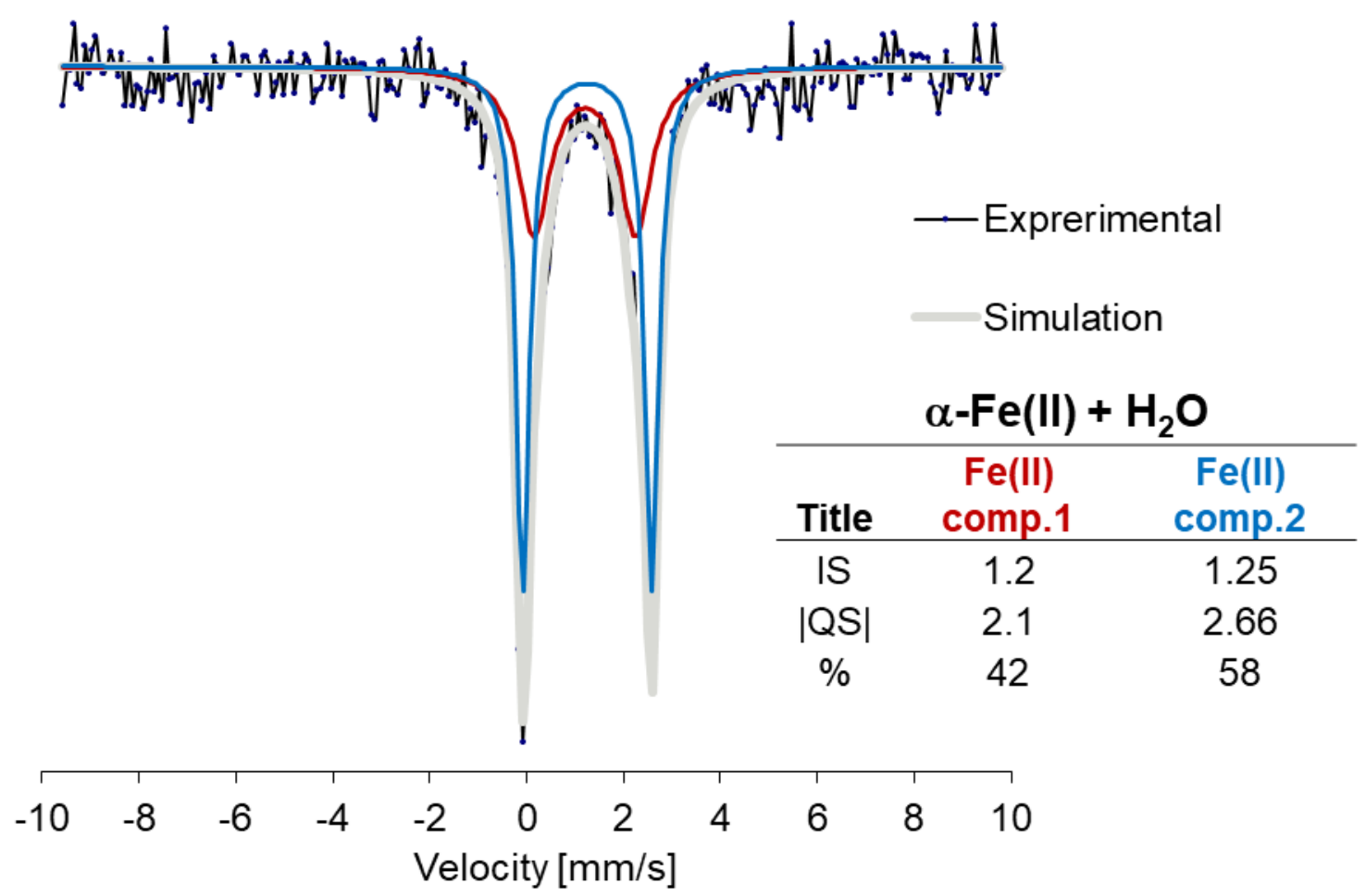

Figure S24: Deconvoluted room temperature Mössbauer spectrum of a 100\% $\alpha$-Fe(II) sample exposed to water 


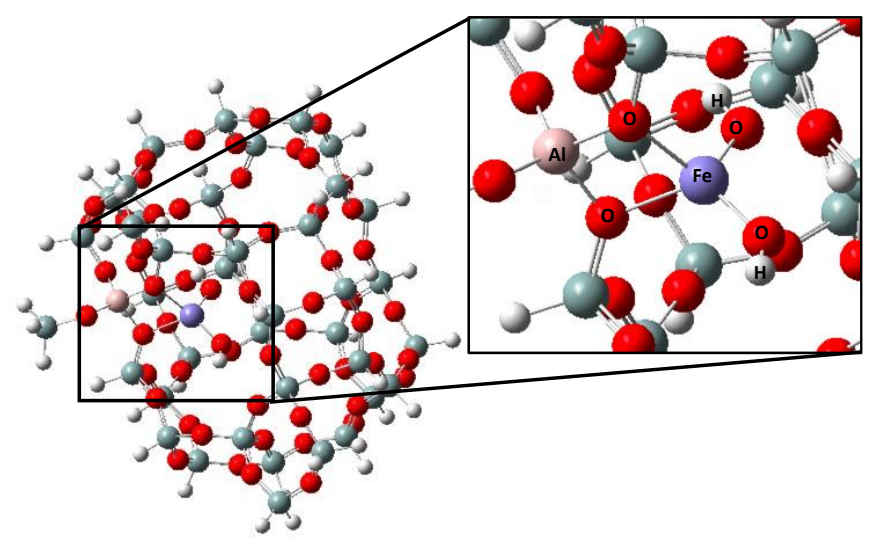

Figure S25: Geometry optimized DFT cluster model of a CHA cage with a $\left[\mathrm{Fe}(\mathrm{OH})_{2}\right]^{+}$site.

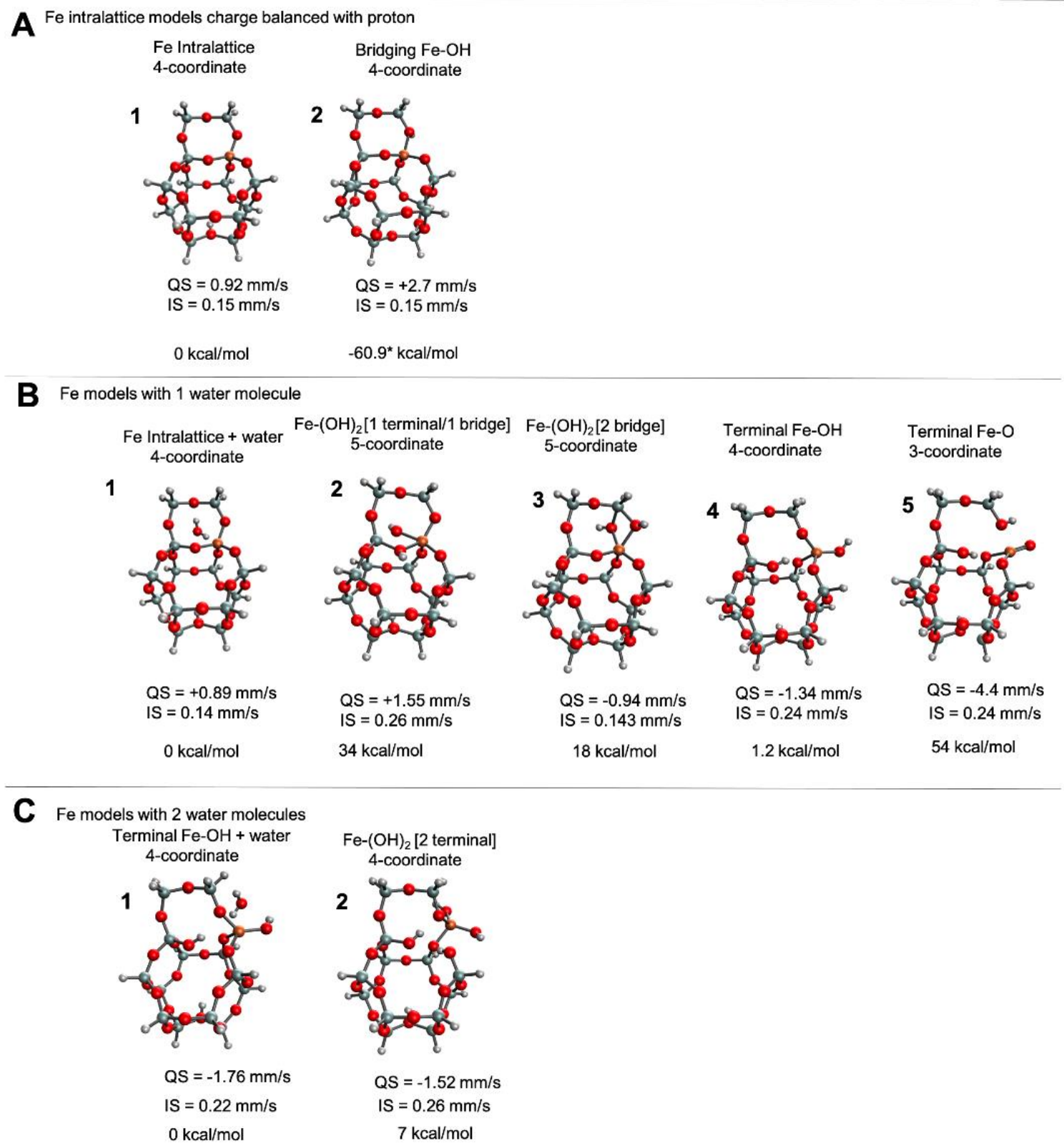

Figure S26: DFT structures, their Mössbauer parameters, and their respective energies (within the same amount of water molecules) for the set of structural models analyzed to assess the hydrolysis of Fe(III)-OFw bonds. * indicates an over estimation of energy stabilization by moving a proton closer to a Fe(III) atom. 


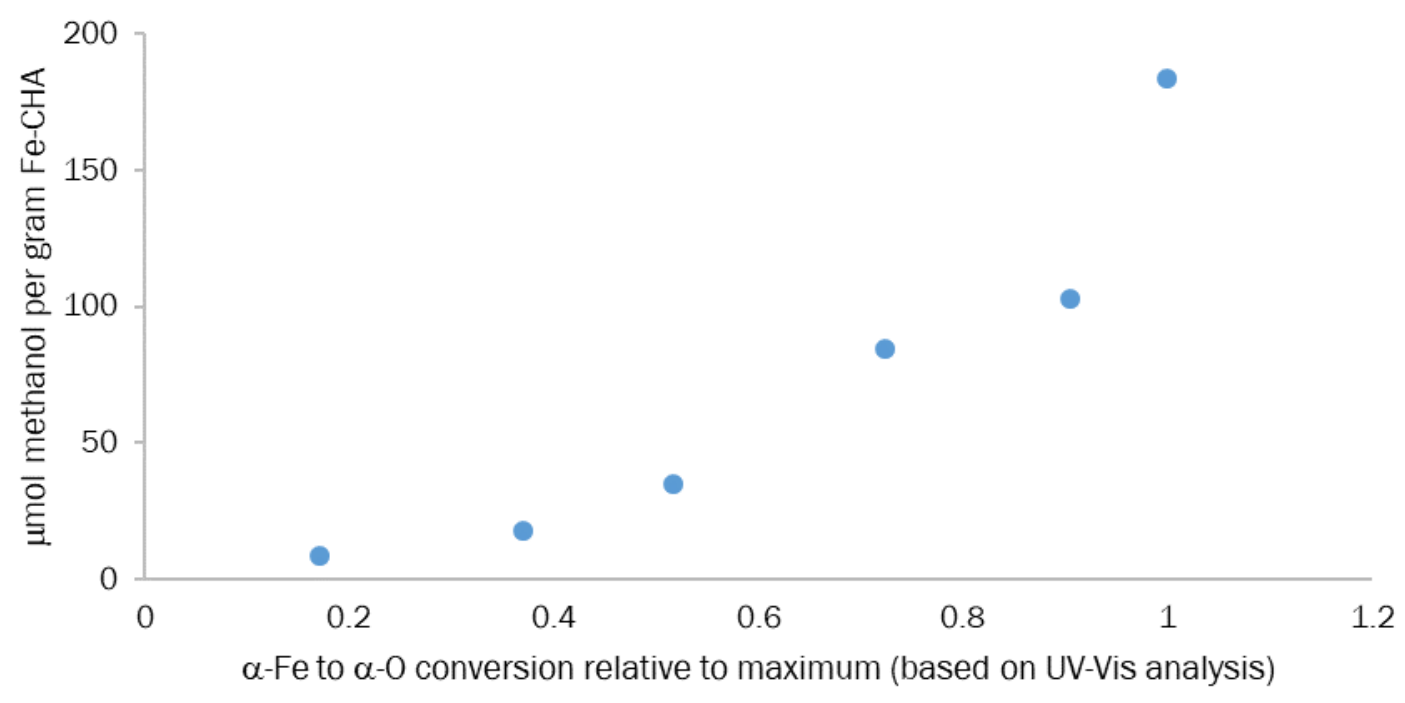

Figure S27: correlation of extractable methanol in room temperature steaming $\left(\mathrm{H}_{2} \mathrm{O}\right.$ saturated He stream) from 2 grams of a one-pot IZC prepared Fe-CHA sample with Fe loading 1.86 wt.\% with different degrees of $\alpha$ - $\mathrm{Fe}(\mathrm{II})$ to $\alpha-\mathrm{O}$ conversion with $\mathrm{N}_{2} \mathrm{O}$. The sample was first activated at $900^{\circ} \mathrm{C}$ in dried Helium, then exposed to $35 \% \mathrm{~N}_{2} \mathrm{O}$ in He atmosphere at room temperature, then heated for 25 minutes at 100,120,130,140, 160 or $180^{\circ} \mathrm{C}$, and then reacted with $\mathrm{CH}_{4}$ at room temperature. UV-VisNIR spectra were measured after each treatment step. The MS signal was referenced to the $\mathrm{m} / \mathrm{z}=4$ signal as internal standard, and converted to methanol through a calibration with amounts of methanol adsorbed onto a zeolite and then desorbed as in the experiments. 


\section{S13. References}

(1) Bols, M. L.; Hallaert, S. D.; Snyder, B. E. R.; Devos, J.; Plessers, D.; Rhoda, H. M.; Dusselier, M.; Schoonheydt, R. A.; Pierloot, K.; Solomon, E. I.; Sels, B. F. Spectroscopic Identification of the $\alpha-\mathrm{Fe} / \alpha-\mathrm{O}$ Active Site in Fe-CHA Zeolite for the Low-Temperature Activation of the Methane C-H Bond. J. Am. Chem. Soc. 2018, 140, 1202112032.

(2) Snyder, B. E. R.; Vanelderen, P.; Bols, M. L.; Hallaert, S. D.; Böttger, L. H.; Ungur, L.; Pierloot, K.; Schoonheydt, R. A.; Sels, B. F.; Solomon, E. I. The Active Site of Low-Temperature Methane Hydroxylation in Iron-Containing Zeolites. Nature 2016, 536, 317-321.

(3) Devos, J.; Bols, M. L.; Plessers, D.; Goethem, C. Van; Seo, J. W.; Hwang, S.-J.; Sels, B. F.; Dusselier, M. Synthesis-Structure-Activity Relations in Fe-CHA for $\mathrm{C}-\mathrm{H}$ Activation: Control of Al Distribution by Interzeolite Conversion. Chem. Mater. 2020, 32, 273-285.

Hallaert, S. D.; Bols, M. L.; Vanelderen, P.; Schoonheydt, R. A.; Sels, B. F.; Pierloot, K. Identification of $\alpha$-Fe in High-Silica Zeolites on the Basis of Ab Initio Electronic Structure Calculations. Inorg. Chem. 2017, 56, 1068110690.

Snyder, B. E. R.; Bols, M. L.; Rhoda, H. M.; Vanelderen, P.; Böttger, L. H.; Braun, A.; Yan, J. J.; Hadt, R. G.; Babicz, J. T.; Hu, M. Y.; Zhao, J.; Alp, E. E.; Hedman, B.; Hodgson, K. O.; Schoonheydt, R. A.; Sels, B. F.; Solomon, E. I. Mechanism of Selective Benzene Hydroxylation Catalyzed by Iron-Containing Zeolites. Proc. Natl. Acad. Sci. 2018, 115, 12124-12129.

(6) Snyder, B. E. R.; Böttger, L. H.; Bols, M. L.; Yan, J. J.; Rhoda, H. M.; Jacobs, A. B.; Hu, M. Y.; Zhao, J.; Alp, E. E.; Hedman, B.; Hodgson, K. O.; Schoonheydt, R. A.; Sels, B. F.; Solomon, E. I. Structural Characterization of a Non-Heme Iron Active Site in Zeolites That Hydroxylates Methane. Proc. Natl. Acad. Sci. 2018, 115, 4565-4570.

(7) Joichi, Y.; Shimono, D.; Tsunoji, N.; Takamitsu, Y.; Sadakane, M.; Sano, T. Stepwise Gel Preparation for HighQuality CHA Zeolite Synthesis: A Common Tool for Synthesis Diversification. Cryst. Growth \&amp; Des. 2018, $18,5652-5662$

(8) Ravi, M.; Sushkevich, V. L.; Van Bokhoven, J. A. Lewis Acidity Inherent to the Framework of Zeolite Mordenite. J. Phys. Chem. C 2019.

(9) Shantz, D. F.; Lobo, R. F.; Fild, C.; Koller, H. Controlling the Distribution of Framework Aluminum in High-Silica Zeolites. Stud. Surf. Sci. Catal. 2000, 130 A, 845-850.

(10) Mlekodaj, K.; Dedecek, J.; Pashkova, V.; Tabor, E.; Klein, P.; Urbanova, M.; Karcz, R.; Sazama, P.; Whittleton, S. R.; Thomas, H. M.; Fishchuk, A. V.; Sklenak, S. Al Organization in the SSZ-13 Zeolite. Al Distribution and Extraframework Sites of Divalent Cations. J. Phys. Chem. C 2018, acs.jpcc.8b07343.

(11) Di Iorio, J. R.; Gounder, R. Controlling the Isolation and Pairing of Aluminum in Chabazite Zeolites Using Mixtures of Organic and Inorganic Structure-Directing Agents. Chem. Mater. 2016, 28, 2236-2247.

(12) Gallup, D. L. Aluminum Silicate Scale Formation and Inhibitor (2): Scale Solubilities and Laboratory and Field Inhibition Tests. Geothermics 1998, 27, 485-501.

(13) Fedeyko, J. M.; Egolf-Fox, H.; Fickel, D. W.; Vlachos, D. G.; Lobo, R. F. Initial Stages of Self-Organization of Silica-Alumina Gels in Zeolite Synthesis. Langmuir 2007.

(14) Ruiz-Agudo, E.; Putnis, C. V.; Putnis, A. Coupled Dissolution and Precipitation at Mineral-Fluid Interfaces. Chemical Geology. Elsevier September 2014, pp 132-146. 
(15) Fejes, P.; Nagy, J. B.; Halász, J.; Oszkó, A. Heat-Treatment of Isomorphously Substituted ZSM-5 Zeolites and Its Structural Consequences. An X-Ray Diffraction, 29Si MAS-NMR, XPS and FT-IR Spectroscopy Study. Appl. Catal. A Gen. 1998, 175, 89-104.

(16) Kumar, R.; Raj, A.; Kumar, S. B.; Ratnasamy, P. Convenient Synthesis of Crystalline Microporous Transition Metal Silicates Using Complexing Agents. Stud. Surf. Sci. Catal. 1994, 84, 109-116.

(17) Dubkov, K. A.; Paukshtis, E. A.; Panov, G. I. Stoichiometry of Oxidation Reactions Involving $\alpha$-Oxygen on FeZSM-5 Zeolite. Kinet. Catal. 2001, 42, 205-211.

(18) Jackson, R. B.; Solomon, E. I.; Canadell, J. G.; Cargnello, M.; Field, C. B. Methane Removal and Atmospheric Restoration. Nat. Sustain. 2019, 2, 436-438.

(19) Panov, G. I.; Starokon, E. V.; Pirutko, L. V.; Paukshtis, E. A.; Parmon, V. N. New Reaction of Anion Radicals Owith Water on the Surface of FeZSM-5. J. Catal. 2008, 254, 110-120.

(20) Bordiga, S.; Lamberti, C.; Bonino, F.; Travert, A.; Dé, F.; Thibault-Starzyk, R. Probing Zeolites by Vibrational Spectroscopies. Chem. Soc. Rev 2015, 44, 7262.

(21) Karge, H. G.; Geidel, E. Vibrational Spectroscopy. In Molecular Sieves - Science and Techology; Springer-Verlag: Berlin, 2004; pp 1-200.

(22) Karge, H. G. Characterization by IR spectroscopy http://www.izaonline.org/synthesis/VS_2ndEd/IR_Spectroscopy.htm (accessed Nov 12, 2017).

(23) Di Iorio, J. R.; Li, S.; Jones, C. B.; Nimlos, C. T.; Wang, Y.; Kunkes, E.; Vattipalli, V.; Prasad, S.; Moini, A.; Schneider, W. F.; Gounder, R. Cooperative and Competitive Occlusion of Organic and Inorganic StructureDirecting Agents within Chabazite Zeolites Influences Their Aluminum Arrangement. J. Am. Chem. Soc. 2020.

(24) Devos, J.; Robijns, S.; Van Goethem, C.; Khalil, I.; Dusselier, M. Interzeolite Conversion and the Role of Aluminum: Toward Generic Principles of Acid Site Genesis and Distributions in ZSM-5 and SSZ-13. Chem. Mater. 2021. 